\title{
Winter mixing impacts gene expression in marine microbial populations in the Gulf of Aqaba
}

\author{
D. Miller ${ }^{1}$, U. Pfreundt ${ }^{2,3}$, S. Hou ${ }^{2}$, S. C. Lott ${ }^{2}$, W. R. Hess ${ }^{2}$, I. Berman-Frank ${ }^{1, *}$ \\ ${ }^{1}$ Mina and Everard Goodman Faculty of Life Sciences, Bar Ilan University, Ramat Gan, Israel \\ ${ }^{2}$ Genetics and Experimental Bioinformatics, Faculty of Biology, University of Freiburg, Schänzlestr. 1, 79104 Freiburg, Germany \\ ${ }^{3}$ Present address: ETH Zürich, Department of Civil, Environmental and Geomatic Engineering, \\ Institute of Environmental Engineering, Stefano-Franscini-Platz 5, 8093 Zürich, Switzerland
}

\begin{abstract}
In aquatic systems, changes in temperature and irradiance fundamentally characterize the water column and regulate microbial population structure and function. In systems with stable thermal stratification, the warm surface mixed layer is typically nutrient impoverished, limiting biological production. In periods of destratification, convective mixing of the water column exposes the microorganisms inhabiting these mixed systems to rapid variations in light availability and spectra. We explored the impact of winter deep-mixing (500 $\mathrm{m}$ deep mixed layer) on microbial communities from the surface $(2.5 \mathrm{~m})$ and the aphotic waters $(440 \mathrm{~m})$ in the Gulf of Aqaba by examining changes in both population composition and function via DNA and RNA sequencing. The greatest fraction of $16 \mathrm{~S}$ sequences was assigned to Euryarchaeota, while metatranscriptomes were dominated by Synechococcus transcripts. Community composition was highly similar at both depths, yet transcription profiles differed. Phototrophic organisms found at the photic surface overexpressed genes related to catabolism and energy metabolism, while genes affiliated with biosynthesis were overexpressed at the aphotic depth. Similar transcriptional trends were observed in the non-photoautotrophs SAR11, Euryarchaeota, and Thaumarchaeota, with niche partitioning based on differential utilization of nitrogen and phosphorus occurring between the 2 archaeal groups. We did not detect upregulated expression of cyanobacterial genes indicative of mixotrophy or glycogen metabolism in the aphotic zone, suggesting they survive the aphotic period by utilizing photosynthates produced in the photic zone. Indications for a mixotrophic lifestyle were observed for prasinophytes, with genes related to phagocytosis overexpressed at the aphotic depth compared with the surface.
\end{abstract}

KEY WORDS: Deep mixing $\cdot$ Red Sea $\cdot$ Metatranscriptomics $\cdot$ Cyanobacteria $\cdot$ SAR11 Archaea Prasinophytes

\section{INTRODUCTION}

Irradiance is a primary driver of phototroph distribution and physiology in aquatic systems, where the exponential decay of light intensity and changing spectra define a gradient of environments and create photic and aphotic zones. Seasonal thermal stratification and destratification cycles further impact the vertical distribution of microbial organisms throughout the water column. In fully stratified systems,

\footnotetext{
*Corresponding author: ilana.berman-frank@biu.ac.il
}

planktonic microbial cells may be exposed regularly to diel light cycles or inhabit the aphotic (dark) zone. In seasonally mixed water columns, cells are often driven across the photic boundary by vertical mixing. In these dynamic environments, planktonic microorganisms develop strategies that allow their survival in a rapidly changing environment with varying light conditions. Several studies have assessed the differences in microbial community composition and functionality between different layers of the water col-

(C) The authors 2017. Open Access under Creative Commons by Attribution Licence. Use, distribution and reproduction are unrestricted. Authors and original publication must be credited. 
umn (Ghiglione et al. 2007, 2008, Tamburini et al. 2009, Korlević et al. 2015). In metagenomic surveys from oligotrophic stratified environments, including the northwest Pacific Ocean and the Sargasso, Mediterranean, and Red Seas, Prochlorococcus, Verrucomicrobiales, Flexibacteraceae, Euryarchaeota, and Gamma-, Delta-, and Alphaproteobaceria dominated surface-water microbial populations (DeLong et al. 2006, Ferreira et al. 2014, Thompson et al. 2017). The dominant metabolic pathways in surface waters (based on sequence similarity searches of metagenome sequences against protein data bases) included chlorophyll and carotenoid biosynthesis, carbon fixation, light-induced DNA repair, oxidative stress responses, nitrogen and phosphate metabolism, and vitamin B6 metabolism (DeLong et al. 2006, Ferreira et al. 2014, Thompson et al. 2017). At aphotic depths, representatives from Deferribacteres, Planctomycetaceae, Acidobacteriales, Gemmatamonadaceae, Nitrospina, Alteromonadaeceae, and Thaumarchaeota prevailed (DeLong et al. 2006, Ferreira et al. 2014), while characteristic metabolic functions included protein folding and export, glyoxylate and dicarboxylate metabolism, thiamine metabolism, methane oxidation, selenocysteine metabolism and terpenoid biosynthesis, and sulfate assimilation and metabolism (DeLong et al. 2006, Ferreira et al. 2014). Hence, taxonomic and functional profiles characterizing certain depths can be established from nucleic acid sequencing assays. However, vertical mixing can modify these characteristic profiles, as described from the Humboldt Current upwelling system along the Chilean coastline (Ferreira et al. 2014).

The restricted influx of cold water over a shallow southern sill produces high minimal temperatures $\left(\sim 20.6^{\circ} \mathrm{C}\right)$ throughout the water column of the northern Gulf of Aqaba, Red Sea (Reiss \& Hottinger 1984). During summer stratification, typical surface temperatures reach $28^{\circ} \mathrm{C}$ and the mixed layer depth is $<30 \mathrm{~m}$. With declining fall-winter air temperatures, the upper layer cools and sinks, causing destratification, and mixing may typically reach 300-400 $\mathrm{m}$ by late February/early March and can deepen to $~ 800 \mathrm{~m}$ during extremely cold winters (Wolf-Vecht et al. 1992, Genin et al. 1995, Carlson et al. 2014).

This deep mixing results in a fairly uniform distribution of the picoplanktonic populations of Prochlorococcus, Synechococcus, and unicellular eukaryotic algae within the mixed water column, including the aphotic depths (Lindell \& Post 1995). Here, we examined the microbial population structure and function from a photic and aphotic depth in the northern Gulf of Aqaba during winter deep mixing that reached
$500 \mathrm{~m}$ depth. We assessed and analyzed the contribution of taxonomic groups within the microbial community from photic and aphotic depths by $16 \mathrm{~S}$ gene sequencing. Concurrently, we analyzed microbial transcriptional activity using metatranscriptomics. To capture genes that are expressed as a response to changes associated with convection, we assessed only nascent (recently transcribed) transcripts using meta-differential RNA-seq (mdRNAseq, Hou et al. 2016). We further analyzed the data examining the ecophysiological implications for representative species from abundant taxa, including photoautotrophic cyanobacteria, photoheterotrophic bacteria (SAR11), archaea, and picoeukaryotic algae.

\section{MATERIALS AND METHODS}

\section{Sampling procedures and site}

Samples were collected on 5 February 2012 at Stn A in the Gulf of Aqaba $\left(29^{\circ} 28^{\prime} \mathrm{N}, 34^{\circ} 55^{\prime} \mathrm{E}\right.$, $\sim 700 \mathrm{~m}$ bottom depth) from 2 depths at 09:45 h $(2.5$ and $440 \mathrm{~m}$ ) and from $45 \mathrm{~m}$ at 14:45 h (GMT +2). The sample collected in the afternoon was obtained in the framework of a different project aiming to compare dRNA-seq (see below) with standard RNA-seq (Hou et al. 2016). We also used the $45 \mathrm{~m}$ sample for the investigation of $16 \mathrm{~S}$-based community composition and taxonomic assignment of RNA reads (see Fig. 2). Water samples were obtained using a rosette device equipped with 12 Niskin bottles of 10 l each and CTD sensors detecting temperature, salinity, chlorophyll a (chl a)-induced fluorescence, oxygen, and photosynthetically active radiation (PAR). For each RNA sample, $10 \mathrm{l}$ of water were collected from each of 4 Niskin bottles and immediately filtered in a shaded area onboard through a $20 \mu \mathrm{m}$ mesh onto polyethersulfone filters (PALL Supor, $47 \mathrm{~mm}$ diameter, $0.45 \mu \mathrm{m}$ pore size). Minimal volume filtered was $2.6 \mathrm{l}$ and maximal volume reached approximately 5 l. Filtration time did not exceed 20 min to minimize filtration stress and expression of genes resulting from filtration and environmental shift. The duration of the deepest cast was approximately $30 \mathrm{~min}$ from the deepest point $(\sim 700 \mathrm{~m})$ to the surface, and $\sim 20 \mathrm{~min}$ were required for the $440 \mathrm{~m}$ sample to reach the deck. Filters were subsequently placed in $1 \mathrm{ml}$ of RNA resuspension buffer (10 mM NaOAc pH 5.2, 200 mM D (+)-sucrose, 100 mM NaCl, 5 mM EDTA), immediately frozen in liquid nitrogen, and kept at $-80^{\circ} \mathrm{C}$ until further analysis. RNA extraction and library preparation was performed according to the 
mdRNA-seq approach (Sharma et al. 2010, Hou et al. 2016). The procedure is described below and detailed in Supplement 1 at www.int-res.com/articles/ suppl/a080p223_supp1.pdf.

\section{Inorganic nutrient measurements}

Seawater for inorganic nutrient analyses (orthophosphate, nitrate, and nitrite) was collected in acidwashed plastic $20 \mathrm{ml}$ vials. Samples were immediately frozen and thawed upon analysis. Nutrient concentrations were determined colorimetrically using a flow injection autoanalyzer (FIA Lachat Instruments Model QuickChem 8000). Peak areas were calibrated using standards prepared with nutrient-depleted filtered sea water. Phosphate was preconcentrated by a factor of 20 by applying the magnesium co-precipitation (MAGIC) protocol (Karl \& Tien 1992). The precision of nitrate + nitrite and orthophosphate measurements was 0.05 and $0.02 \mu \mathrm{M}$, respectively.

\section{Flow cytometry}

Picophytoplankton cell abundance was determined using flow cytometry. Samples of $1.8 \mathrm{ml}$ were fixed immediately after sampling with $5 \mu$ of $50 \%$ glutaraldehyde (Sigma G-7651), incubated at room temperature for $10 \mathrm{~min}$, frozen in liquid nitrogen, and kept at $-80^{\circ} \mathrm{C}$ until further analysis. Prior to the analysis, fixed samples were gradually thawed in a $37^{\circ} \mathrm{C}$ water bath. Analysis was performed using a FACScan Attune, fitted with argon lasers (405 and $488 \mathrm{~nm}$ ). Beads of $1 \mu \mathrm{m}$ diameter (Polysciences) served as standards (Marie et al. 1997, Sosik et al. 2010). The taxonomic discrimination was based on cell side scatter (a proxy of cell volume), forward scatter (a proxy of cell size), and orange and red fluorescence of phycoerythrin and chl a (filters: 574/26 nm band pass and $640 \mathrm{~nm}$ long pass, respectively). Phytoplankton carbon (C) biomass was calculated from cell counts assuming $225 \mathrm{fg} \mathrm{C}$ cell $^{-1}$ for Synechococcus cells, $60 \mathrm{fg}$ C cell ${ }^{-1}$ for Prochlorococcus cells, and $1319 \mathrm{fg} \mathrm{C}^{\mathrm{C}} \mathrm{cell}^{-1}$ for picoeukaryotes (Buitenhuis et al. 2012).

\section{DNA extraction and amplification of 16S rRNA gene sequences}

Water samples (2 l) were filtered on $47 \mathrm{~mm}, 0.45 \mu \mathrm{m}$ pore size Supor filters (Pall Gelman) and snap frozen in liquid nitrogen. The filters were kept at $-80^{\circ} \mathrm{C}$ until
DNA extraction, performed with phenol-chloroform using a modification of the protocols described by Brinkhoff \& Muyzer (1997) and Massana et al. (1997). For amplicon sequencing, we used the primer pair S-DBact-0341-b-S-17/S-D-Bact-0785-a-A-21 (Klindworth et al. 2013), which targets the V3-V4 region of the $16 \mathrm{~S}$ rRNA gene of bacteria and archaea. Amplicons were sequenced on a MiSeq Illumina ${ }^{\mathrm{TM}}$ sequencer in pairedend mode (300 bp $\times 2$ per fragment).

\section{RNA extraction and library preparation}

The RNA sampling procedure was described elsewhere (Pfreundt et al. 2014). Briefly, sampled seawater was filtered onboard in a shaded working space directly upon retrieval of the rosette, for no longer than $20 \mathrm{~min}$. Water samples were pre-filtered using a $20 \mu \mathrm{m}$ mesh onto $0.45 \mu \mathrm{m}$ pore size polyethersulfone filters (PALL Supor). Filters were immediately placed in $1 \mathrm{ml}$ of RNA resuspension buffer $(10 \mathrm{mM} \mathrm{NaAc} \mathrm{pH}$ 5.2, $200 \mathrm{mM} \mathrm{D(+)} \mathrm{sucrose,} 100 \mathrm{mM} \mathrm{NaCl}, 5 \mathrm{mM}$ EDTA) and snap frozen in liquid nitrogen. Samples were kept at $-80^{\circ} \mathrm{C}$ until further processing.

Total RNA was extracted using phenolic PGTX (modified from Pinto et al. 2009), DNAse treated (Ambion), and purified (Clean\&Concentrator ${ }^{\circledR}$ columns Zymo Research). dRNA-seq libraries were prepared according to Sharma et al. (2010). RNA molecules carrying a 5' monophosphate were degraded using Terminator exonuclease (Epicentre), and the 5' sequencing adapter (including sample barcode) was ligated. This resulted in a library highly enriched in nascent transcripts. cDNA first-strand synthesis was performed using random hexameric primers followed by the ligation of a second PCR adapter at the original 3' end of the RNA (now found at the 5' end of the cDNA first strand). The resulting CDNA molecules were then PCR amplified using biotinylated 5' primers, and PCR products were fragmented by sonication. Fragments of 300-500 bp were size-selected and attached to streptavidin beads, and the 3' Illumina sequencing adapter was ligated. Bead-bound fragments were subjected to a second, short PCR amplification and sequenced on an Illumina Hi-Seq platform. This procedure resulted in a library of reads originating at the $5^{\prime}$ end of the transcripts present in the sample, allowing downstream analyses to determine the real transcription start site (TSS) of the transcript (see below).

All raw reads were uploaded to the NCBI Sequence Read Archive (SRA) under the BioProject accession number PRJNA248420. 


\section{Analysis of $16 \mathrm{~S}$ gene sequence abundance and microbial population composition}

The analysis pipeline of $16 \mathrm{~S}$ amplicons was followed as described by Pfreundt et al. (2016b). Briefly, all steps of the bioinformatic analysis were performed using the USEARCH pipeline and the UPARSE package (Edgar 2013). Reads in fastq format were quality filtered and converted to fasta format before clustering $100 \%$ identical reads, discarding singletons, and defining operational taxonomic unit (OTU) clusters (maximum dissimilarity of $2 \%$ ). Chimeras were auto-filtered by the OTU clustering algorithm. OTUs were mapped to the SILVA SSU database (release 119.1; https://www.arb-silva.de/). The threshold for classification was ( $\%$ sequence identity $+\%$ sequence coverage) $/ 2>93 \%$.

\section{Bioinformatics analysis of metatranscriptomes}

For a more detailed description of bioinformatics approaches, see Supplement 1.

The complete analysis pipeline of metatranscriptome libraries is visualized in Fig. S1 (all supplementary figures are available in Supplement 1). Following sequencing, raw reads were subjected to quality control, adapter trimming, and computational removal of rRNA reads. The obtained sequences were subjected to similarity searches against the NCBI nt database (downloaded in March 2016 from ftp://ftp.ncbi.nlm.nih.gov/blast/ $\mathrm{db} /$ ) using LAST (Kiełbasa et al. 2011). The LAST search was performed with default parameters using the 'BlastTab+' output option except for the following switches: -K 10 and -N 25 (see LAST documentation for further details). The taxonomic affiliations of transcriptome reads were analyzed using MEGAN 5.

We used reference genomes obtained from the RefSeq database (Tatusova et al. 2014) instead of a selfassembled reference. A former approach trying to de novo assemble the metatranscriptomes into transcripts and use them as references did not yield satisfactory results (Pfreundt et al. 2014). This was likely due to the fact that dRNA-seq enriches the sequence library with reads assigned to the $5^{\prime}$ end of transcripts, restricting the distribution of reads over the full transcript length. In addition, concerns have been raised in the past regarding the assembly of reads emerging from complex communities of metagenomes and metatranscriptomes (Charuvaka \& Rangwala 2011, Mende et al. 2012).
Reference genomes were identified for each taxonomic group separately. For cyanobacteria, the majority of reads were mapped to the Synechococcus CC9605 genome (21 and $44 \%$ for 2.5 and $440 \mathrm{~m}$ ). In the case of SAR11, the 3 complete genomes found in the RefSeq database were compared as references for all reads assigned to SAR11 using dc-megablast. Pelagibacter sp. HTCC7211 recruited the highest percentage of reads ( 38 and $43 \%$ ) and was selected as a reference. No suitable reference genome could be found in RefSeq for Euryarchaeota or Thaumarchaeota. To generate a reference for mapping, archaeal reads were first mapped to a set of 997 archaeal contigs from a Mediterranean Sea metagenomics library (Deschamps et al. 2014). Contigs recruiting at least 200 reads were extracted and used as a reference. This resulted in a reference composed of 115 contigs ascribed to the Euryarchaeota MG-II/III and a second reference for Thaumarchaeota, composed of 107 contigs. These references recruited $56-95 \%$ of all archaeal reads. A separately defined set of MG-II/III genomic bins (Li et al. 2015) did not improve this recruitment. All annotations used were based on the original annotations of the 997 published contigs. The Micromonas sp. RCC299 genome, which recruited 74 and $71 \%$ of Mamiellales reads at 2.5 and $440 \mathrm{~m}$, respectively, was selected as a representative of this group.

Expression levels were defined as the averaged forward and reverse read counts assigned to a transcript (coding sequences, non-coding RNA, rRNA, and tRNA genes) for which a TSS was detected (hereafter: TSS expression). In some cases, transcripts without a detected TSS but with a clearly high recruitment of reads were also considered in the final analysis.

Following mapping to reference genomes, TSSs were inferred as previously described (Hou et al. 2016) and outlined in Supplement 1. After detecting TSSs, averaged values of counts of forward and reverse reads assigned to each TSS were used as a measure for expression level of the associated gene. These values were compared between the different depths for differential expression (DE) analysis using NOISeq (Tarazona et al. 2011). The calculation of DE was based on trimmed mean of M (TMM)-normalized TSS expression values (Robinson \& Oshlack 2010) using 5 technical repeat simulations, each representing $20 \%$ of complete sample size. Variability of $2 \%$ was presumed, and the probability threshold for DE was set to 0.9 . Transcripts with $<2$ counts per million were excluded from the analysis. Since the length of each examined feature (transcript) is known from the reference genome, length correction was also included in the analysis. In some cases, 2 
different TSSs of the same gene were differentially expressed, indicating possibly alternatively regulated promoters. Since no data were available on the different functions of such hypothetical transcripts, they were treated as synonymous and were considered as differentially expressed when the TMM value of an overexpressed transcript in one sample was at least 3-fold higher compared to the TMM value of the other transcript, detected as overexpressed in the other sample.

Protein sequences of all transcripts identified for each of the reference genomes were used for BlastKOALA searches (Kanehisa et al. 2016) against the Kyoto Encyclopedia of Genes and Genomes (KEGG) database (Kanehisa \& Goto 2000). The resulting KEGG-orthologs (KOs) were visualized using iPath2.0 (Yamada et al. 2011). The procedure was also performed on lists of differentially expressed KO numbers, and depth-specific functional profiles were generated in the form of heat maps visualizing the number of differentially expressed KOs recruited to KEGG pathways at each depth.

\section{RESULTS AND DISCUSSION}

\section{Defining environmental conditions}

Samples were collected on 5 February 2012 at Stn A in the northern Gulf of Aqaba $\left(29^{\circ} 28^{\prime} \mathrm{N}\right.$, $34^{\circ} 55^{\prime} \mathrm{E}$, bottom depth $\sim 700 \mathrm{~m}$ ), when vertical mixing reached a depth of $500 \mathrm{~m}$. Depth profiles of temperature, salinity, dissolved oxygen, inorganic nutrients, and chl a concentrations were reported elsewhere (Pfreundt et al. 2014). Mixed-layer water temperature was $\sim 21.3^{\circ} \mathrm{C}$ (with a minimal difference of $0.1^{\circ} \mathrm{C}$ between the surface and the aphotic samples). Salinity remained stable at 40.7 PSU from the surface to $500 \mathrm{~m}$. The concentrations of inorganic nutrients ranged from 1.7-2.2 $\mu \mathrm{mol} \mathrm{l} \mathrm{l}^{-1} \mathrm{NO}_{3}+\mathrm{NO}_{2}$ (hereafter total inorganic nitrogen, TIN), 0.99$1.08 \mu \mathrm{mol} \mathrm{l}^{-1} \mathrm{Si}(\mathrm{OH})_{4}$, and 0.1-0.12 $\mu \mathrm{mol} \mathrm{l}^{-1} \mathrm{PO}_{4}$. Nutrient concentrations were higher than typical summer values, when surface concentrations decline to $0.05 \mu \mathrm{mol} \mathrm{l}^{-1} \mathrm{TIN}, 0.8 \mu \mathrm{mol} \mathrm{l}^{-1} \mathrm{Si}(\mathrm{OH})_{4}$, and $<0.01$ $0.02 \mu \mathrm{mol} \mathrm{l}^{-1} \mathrm{PO}_{4}$ (Mackey et al. 2007, Lazar et al. 2008, Meeder et al. 2012, Miller et al. 2017), emphasizing the seasonal variability in nutrient availability. The measured winter concentrations were nonetheless comparable to low dissolved inorganic nutrient concentrations measured from the upper surface layers in other oligotrophic locations (Karl et al. 1993, Dore et al. 1996). PAR declined with an absorption coefficient $\left(K_{\mathrm{d}}\right)$ of $0.058 \mathrm{~m}^{-1}$ from $1063 \mu \mathrm{mol}$ quanta $\mathrm{m}^{-2} \mathrm{~s}^{-1}$ at the sea surface to 1 and $0.01 \%$ at 90 and $193 \mathrm{~m}$, respectively (Fig. 1a). Chl a concentration of $0.1 \mathrm{\mu g} \mathrm{l}^{-1}$ was measured throughout the mixed layer and decreased below $500 \mathrm{~m}$ until it was no longer detectable at $567 \mathrm{~m}$ (Pfreundt et al. 2014), consistent with the mixed layer depth.
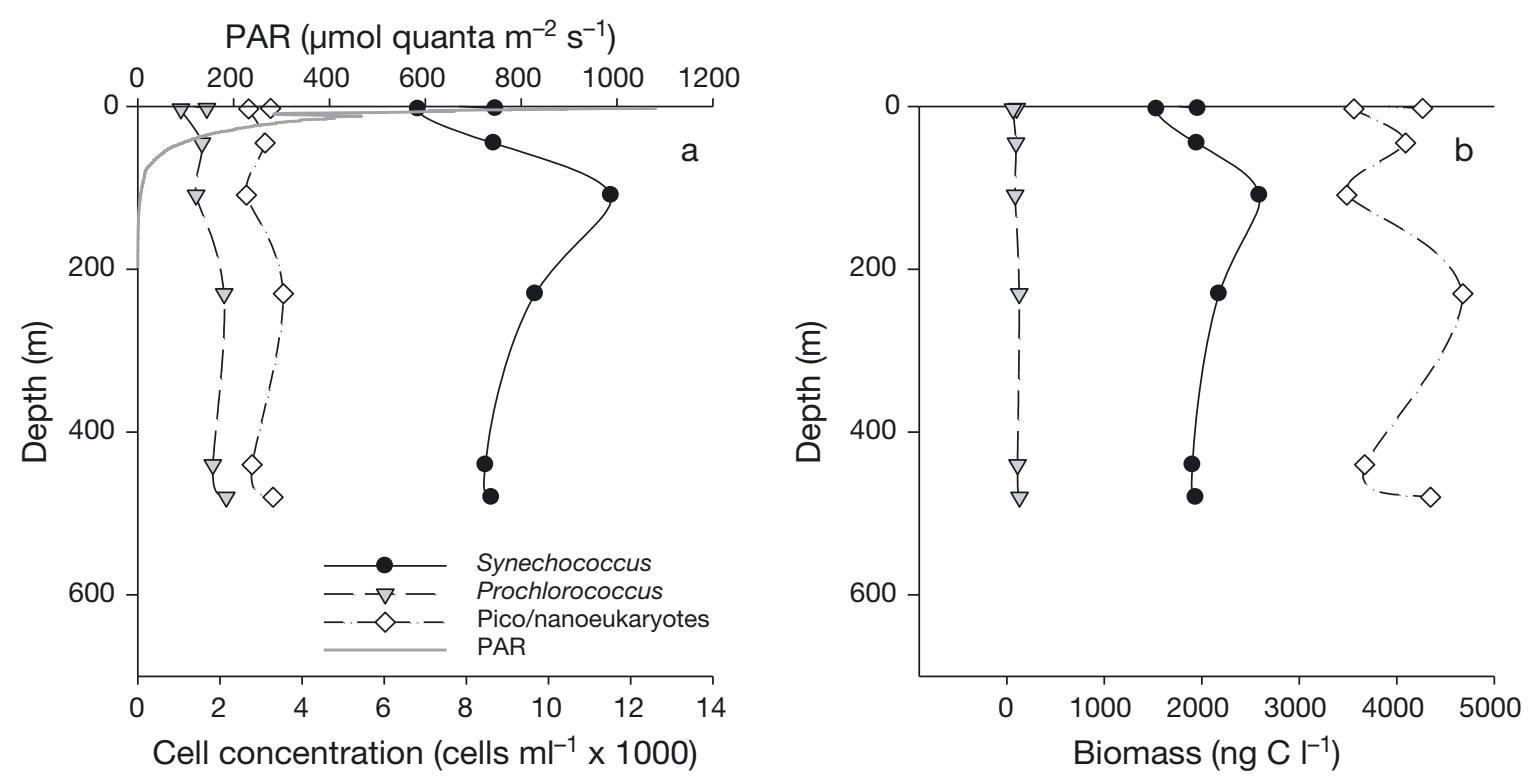

Fig. 1. Distribution of picoplanktonic groups collected on 5 February 2012 at Stn A in the northern Gulf of Aqaba. (a) Depth profiles of Prochlorococcus, Synechococcus, and picoeukaryotic algae cell concentrations based on flow cytometry measurements. Gray solid line shows the intensity of photosynthetically active radiation (PAR) as a function of depth. (b) Phytoplankton carbon biomass for the 3 groups calculated based on cell counts (see 'Materials and methods' for details) 


\section{Photoautotroph abundance}

The predominant contributors to the picophytoplankton (Synechococcus, Prochlorococcus, and picoeukaryotic algae with a diameter of $<3 \mu \mathrm{m}$ ) were distributed throughout the $500 \mathrm{~m}$ mixed layer (Fig. 1). Of the total picophytoplankton biomass, picoeukaryotic algae comprised $72.5-81.8 \%$ (3490-4680 $\mathrm{ng} \mathrm{C} \mathrm{l}^{-1}$ ), followed by $17.2-26.3 \%$ assigned to Synechococcus (1534-2590 ng C $\mathrm{l}^{-1}$ ) and $0.9-1.5 \%$ of the total biomass attributed to Prochlorococcus (63-130 ng C $\mathrm{l}^{-1}$, Fig. 1b). Picoeukaryotes have an average diameter of 2-5 $\mu \mathrm{m}$ compared to the $<1 \mu \mathrm{m}$ of Prochlorococcus and $\sim 1 \mu \mathrm{m}$ of Synechococcus (Olson et al. 1990, Veldhuis \& Kraay 1990). The capacity for luxury uptake and storage of the assimilated nutrients increases with larger cell size (Raven \& Kübler 2002), providing the larger picoeukaryotes with a competitive advantage under higher nutrient concentrations (Kriest \& Oschlies 2007). Therefore, increased nutrient availability caused by seasonal deep mixing enables picoeukaryotic algae to produce more biomass (Lindell \& Post 1995, Mackey et al. 2007). Deep mixing also leads to the circulation of photosynthetic cells throughout the aphotic zone, with chl $a_{2}$, indicative of Prochlorococcus, found at aphotic depth during winter mixing (Lindell \& Post 1995).

Our data show that while Prochlorococcus biomass comprised only $0.9-1.5 \%$ of total picoplankton biomass (Fig. 1), it was the 11th most abundant group within the total classified mRNA pool at 2.5 and $45 \mathrm{~m}$, and the ninth most abundant at $440 \mathrm{~m}$ (contributing $0.2 \%$ in all 3 depths; Fig. 2b). Synechococcus contributed $18-19 \%$ of picophytoplankton biomass, but comprised a relatively low fraction of all $16 \mathrm{~S}$ sequences $(1.3,1.4$, and $2.5 \%$ at $2.5,45$ and $440 \mathrm{~m}$, respectively; Fig. 2a and see below). Yet, the highest fraction of transcripts at the classified mRNA pool at all depths was attributed to this group (Fig. 2b). Active transcription demonstrates that cyanobacteria were present and transcriptionally active throughout the mixed layer, including the aphotic zone. If present for prolonged periods, they could potentially provide an inoculum for rapid growth in the summer, when environmental conditions favor the development of small cells with a large surface area to volume ratio enabling efficient uptake rates.

\section{Population composition and transcriptional activity}

Sequencing of 16S rRNA genes yielded similar (but not identical) composition of microbial populations at
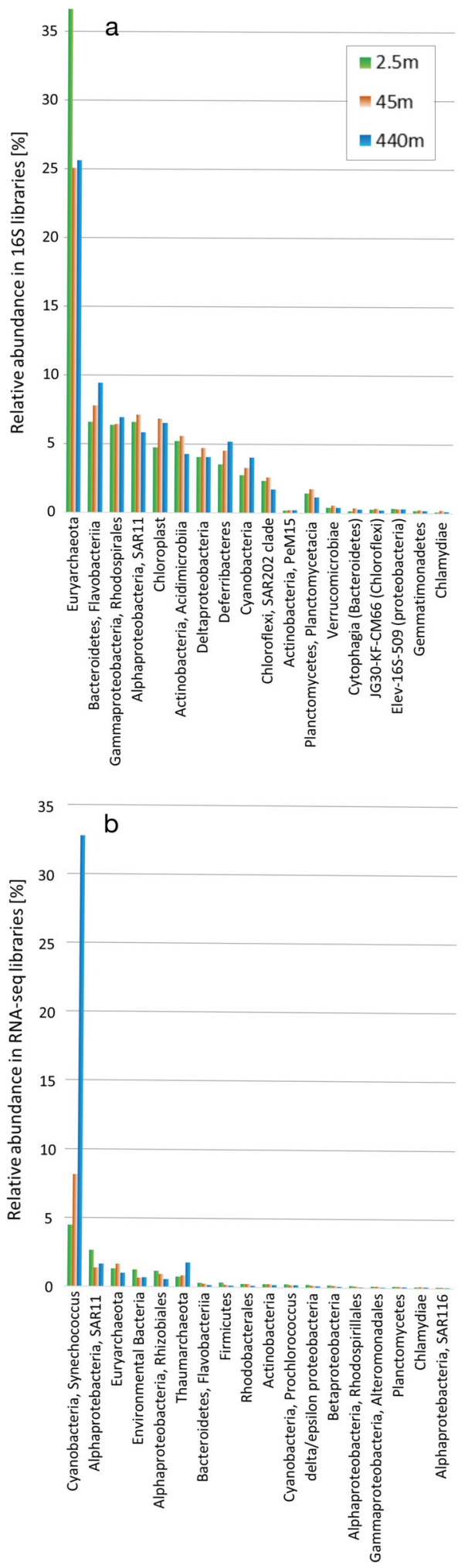

Fig. 2. Relative abundances of the 18 most abundant prokaryotic taxa among (a) 16S rRNA gene amplicon reads and (b) metatranscriptome libraries. Libraries collected from 3 different depths are color labeled. Sequences annotated as 'environmental bacteria' are defined by NCBI as environmental sequences that were classified as bacterial 
2.5 and $440 \mathrm{~m}$ and at $45 \mathrm{~m}$, suggesting convective control of their vertical distribution (Fig. 2a, Table S1 in Supplement 2 at www.int-res.com/articles/suppl/ a080p223_supp2.xlsx; all supplementary tables are available in Supplement 2). The comparable distribution of photosynthetic cyanobacteria in the photic and aphotic layers (Fig. 1) further supports this conclusion. The $45 \mathrm{~m}$ sample was obtained on the same day in the framework of a study that compared different RNA library preparation methods (Hou et al. 2016). However, since this sample was collected several hours after the 2.5 and $440 \mathrm{~m}$ samples, we excluded it from the differential expression analysis performed here (detailed below). Although taxonomically similar, observed variations in population composition suggested that, in addition to convection, parameters such as light, nutrients, and biotic interactions regulated population structure. During a deep convection event $(0-1500 \mathrm{~m})$ in the NW Mediterranean Sea, relatively similar microbial assemblages were obtained throughout the mixed water column, with the observed compositional variations attributed to gradients of nutrients and organic matter (Severin et al. 2016). In a large-scale metagenomic survey across the Red Sea, altered temperature and nitrate concentrations accounted for $>70 \%$ of variation in functional and taxonomic characteristics of the microbial populations (Thompson et al. 2017). Temperature was stable throughout the mixed layer, consistent with the rather modest variations in population composition observed here at different depths (Fig. 2a, Table S1). Our limited sample size precluded detailed comparisons of environmental drivers impacting functional and taxonomic traits between depths (e.g. Thompson et al. 2017).

The velocity of convective mixing currents in the Gulf of Aqaba is currently unknown, but models predict that during winter, mixing currents may reach $1 \mathrm{~cm} \mathrm{~s}^{-1}$ (H. Gildor \& H. Berman pers. comm.). In the NW Mediterranean where deep mixing occurs (Gulf of Lions), convective mixing velocities ranged from 0.3-10.2 $\mathrm{cm} \mathrm{s}^{-1}$ (Schott \& Leaman 1991). Assuming the current velocity to be $\sim 0.3-1 \mathrm{~cm} \mathrm{~s}^{-1}$, it will take 14-46 $\mathrm{h}$ for a picoplanktonic cell to travel a distance of $500 \mathrm{~m}$ (mixed layer depth at the time of sampling). Estimations of Prochlorococcus doubling rates in the field range from 0.2-1.4 doublings $\mathrm{d}^{-1}$ (Partensky et al. 1999). Growth rates from bacterioplankton batch cultures range from $0.07 \mathrm{~d}^{-1}$ for SAR11, $1.05 \mathrm{~d}^{-1}$ in Gammaproteobacteria (Ferrera et al. 2011), and rates of $0.23-0.47 \mathrm{~d}^{-1}$ in cultures of marine archaea (Herndl et al. 2005). In the water column, exposure to various stressors including UV and photo-stress, light deprivation, and high hydrostatic pressure will further alter net growth rates. Taking our conservative estimate of the duration of a complete convection cycle into account, combined with the published range of growth rates, we can assume that division and mortality could have altered the relative abundance of some microbial groups.

The most abundant OTU at all depths was identified as marine group II (MG-II) Euryarchaeota, comprising $36 \%$ of the $16 \mathrm{~S}$ community at $2.5 \mathrm{~m}$ and $\sim 25 \%$ at 440 and $45 \mathrm{~m}$. Our results are consistent with estimates (based on CARD-FISH) of Euryarchaeota and Thaumarchaeota comprising 20-40\% of the prokaryotic community in the Gulf of Aqaba during summer (Ionescu et al. 2009) and suggest that these prokaryotes are abundant throughout the year. Following Euryarchaeota, the most abundant groups were Flavobacteriia $(6.6,7.8$, and $9.4 \%$ at $2.5,45$, and $440 \mathrm{~m}$, respectively), and SAR11 (6.6, 7.1 and $5.8 \%$, respectively; Fig. 2a, Table S1).

Higher relative abundance of certain taxa (SAR11, MG-II Euryarchaeota) detected at the photic compared with the aphotic depth (Fig. 2a) corresponds with their ability to use light as an additional energy source (Béjà et al. 2000, Giovannoni et al. 2005a, DeLong \& Béjà 2010, Iverson et al. 2012). Vertical mixing also enhances availability of phytoplanktonderived particulate and dissolved organic matter (Heimbürger et al. 2013, Gogou et al. 2014, Severin et al. 2014). This organic matter supports the development of bacteria regularly inhabiting the euphotic zone, such as Oceanospirillales and Flavobacteriales (Severin et al. 2016). Furthermore, high-density organic particles provide 'hotspots' supporting microbial populations and facilitating recycling of high molecular weight dissolved organic matter (Kirchman 2002, Teeling et al. 2012, Buchan et al. 2014). This may explain the higher relative abundance of Flavobacteriia at $440 \mathrm{~m}$ depth (Fig. 2a, Table S1).

While direct comparison between 16S amplicon based population composition and RNA-seq based taxonomy of transcriptional activity is problematic (see below), we analyzed the relative share of taxonomic groups in the metatranscriptome by running a similarity search of reads against the NCBI nt database (Fig. 2b). This approach provided a valid estimation of the transcriptional activity of specific taxonomic groups which differed substantially from the 16S-based taxonomic profile (Fig. 2a). Most prominently, the most abundant group in the 16S libraries, Euryarchaeota, was ranked third, second, and fourth at $2.5,45$, and $440 \mathrm{~m}$ (with $1.3,1.6$, and $1.0 \%$, respectively). Similarly, while $16 \mathrm{~S}$ analyses ranked Flavo- 
bacteriia as the second most abundant at all depths with $6.6,7.8$, and $9.4 \%$ at $2.5,45$, and $440 \mathrm{~m}$, their transcriptional activity was low, contributing only $0.3 \%$ to all RNA reads at $2.5 \mathrm{~m}, 0.2 \%$ at $45 \mathrm{~m}$, and only $0.1 \%$ at $440 \mathrm{~m}$. A similar trend was observed for Rhodospirillales, which comprised 6.6, 6.4, and 6.9\% of the $16 \mathrm{~S}$ community at these respective depths, and displayed marginal transcriptional activity at all depths (0.04-0.12\%). Conversely, Synechococcus, with low $16 \mathrm{~S}$ relative abundance $(1.3$ and $2.6 \%$ of the $16 \mathrm{~S}$ community at 2.5 and $440 \mathrm{~m}$, respectively), displayed the highest transcriptional activity, contributing $4.5 \%$ of all RNA reads at $2.5 \mathrm{~m}, 8.1 \%$ at $45 \mathrm{~m}$, and $32.8 \%$ at $440 \mathrm{~m}$. Notably, while Thaumarchaeota were not among the 18 most abundant groups in the 16S libraries, they were ranked sixth, fifth, and second in the RNA-seq libraries from 2.5, 45 and $440 \mathrm{~m}$, respectively (relative abundance: $0.7,0.8$, and $1.8 \%$ ). Ammonia oxidation in Thaumarchaeota is light sensitive (Merbt et al. 2012), consistent with their increasing transcriptional activity at the aphotic depth (Fig. 2b).

For eukaryotes, the above analysis is not suitable for a direct comparison between mRNA and 16S rRNA taxonomic distribution, as such a comparison can underestimate abundance. Eukaryotic organisms only contain 16S rRNA genes in their organelles (chloroplasts and mitochondria), of which the number varies within cells in many eukaryotic groups. Thus, although comprising $8.9-18.5 \%$ of reads in all RNA-seq libraries (see section 'Taxonomic affiliation of mRNA sequence reads' in Supplement 1), eukaryotes were excluded from this analysis.

Differences between the SILVA database and the nt database, and between organisms, further complicate the comparison between 16S-based population composition and the taxonomic affiliation of metatranscriptome reads. Although the vast majority of $16 \mathrm{~S}$ reads map to the SILVA database at any taxonomic level (only 0.06-0.1\% remained unassigned in our libraries), the assignment of metatranscriptome reads (RNA) to taxa using the nt database was more ambiguous (28.9-49.3\% unmapped in our libraries; Table 1). Thus, cultivated and well-studied organisms such as Synechococcus are over represented in the nt database with multiple reference genomes, compared to insufficient coverage of groups with few or no reference genomes.

Nevertheless, although the accuracy of representation of the various taxa is limited, our results highlight differences in tran- scriptional activity between the examined groups. The high transcriptional activity ( $\sim 4.5$ to $\sim 32.8 \%$ compared to $\sim 1.3$ to $\sim 2.5 \%$ of all $16 \mathrm{~S}$ sequences) observed in Synechococcus was not reflected in the groups Euryarchaeota, Flavobacteriia, SAR202, and others (Fig. 2b). Similar discrepancies between 16Sbased population community and taxonomic distribution of RNA reads were found also in Gulf of Mexico microbial communities (Rinta-Kanto et al. 2012). Importantly, the uncoupling of transcript abundance and population composition contributes to the observed differences, with transcript abundance varying on scales of minutes to hours (e.g. Ottesen et al. 2014) compared to the more stable dynamics of population composition. Thus, the time of sampling could further impact the results.

\section{Expression of genes related to metabolic activities in specific taxa}

To gain insight into the ecological roles and interactions within the microbial populations, we assessed detailed gene expression in representatives of diverse ecological groups that dominated the $16 \mathrm{~S}$ and/or metatranscriptome datasets (see Figs. $3 \& 4$, Tables S2 \& S4-S7). We focused on organisms with different ecological roles in the community, with an attempt to shed light on potential interactions and relationships within the microbial population. To assess gene expression in these groups, we mapped group-specific reads to a selected reference genome that recruited the largest fraction of reads of all tested references (see section 'Selection of reference organisms' in Supplement 1). Of all tested cyanobacterial references, the photoautotrophic Synechococcus CC9605 recruited the largest fraction of cyanobacterial reads in our datasets and was thus selected as a representative of the cyanobacteria. The unicel-

Table 1. RNA read counts for each level of analysis in the metatranscriptome quality control (QC) and analysis pipelines. Fw: forward reads, Rev: reverse reads, nt: nucleotide database of NCBI

\begin{tabular}{|lccccc|}
\hline $\begin{array}{l}\text { Depth } \\
(\mathrm{m})\end{array}$ & $\begin{array}{c}\text { Read- } \\
\text { orientation }\end{array}$ & $\begin{array}{c}\text { No. of reads } \\
\text { after QC }\end{array}$ & $\begin{array}{c}\text { Non-rRNA } \\
\text { reads }\end{array}$ & $\begin{array}{c}\text { Reads } \\
\text { mapped } \\
\text { to nt }\end{array}$ & $\begin{array}{c}\text { \% reads } \\
\text { not mapped } \\
\text { to nt }\end{array}$ \\
\hline 2.5 & Fw & 78185262 & 6322603 & - & - \\
& Rev & 77676351 & 6374390 & 3232132 & 49.3 \\
45 & Fw & 71493360 & 6407153 & - & - \\
& Rev & 71291764 & 6461751 & 3489718 & 46 \\
440 & Fw & 81432159 & 35905178 & - & - \\
& Rev & 80859071 & 35505554 & 25243891 & 28.9 \\
\hline
\end{tabular}


lular Micromonas RCC299 of the Mamiellales group recruited the largest fraction of reads, and was chosen to represent the predominant picoeukaryote biomass (Fig. 1b). The third representative, highly abundant in the 16S dataset, was SAR11 (Fig. 2a), a photoheterotrophic alphaproteobacterium considered to be the most abundant bacterial group in the oceans (Morris et al. 2002). We additionally selected 2 groups of archaea, highly abundant in the $16 \mathrm{~S}$ and RNA sequence libraries: Euryarchaeota and Thaumarchaeota.

\section{Cyanobacteria}

Upon assignment of cyanobacterial reads to the Synechococcus CC9605 reference genome, we identified 2595 transcripts using our customized TSS prediction pipeline (see section 'TSS prediction' in Supplement 1). These represented 2055 annotated genes in the selected reference genome. The remaining 540 transcripts are versions of genes with multiple transcription start sites, but since no functional differences between these versions are known, only a single gene sequence was used for KEGG analysis. Of the detected genes, 1057 (51\%) were assigned to KOs (Table 2). We investigated cyanobacterial metabolism by generating a metabolic network based on these KOs (Fig. S3). The analysis demonstrated that genes transcribed by cyanobacteria were predominantly involved in nucleotide and amino-acid metabolism, carbon fixation, carotenoid and folate biosynthesis, and energy metabolism (TCA cycle, glycolysis, ATP synthesis; Fig. S3). To evaluate the expression of genes not considered in the KEGG database, we ranked the list of cyanobacterial transcripts according to the averaged normalized expression values (Table S2). This approach allowed us to complement the list of functions detected by mapping transcripts to the KEGG database and include the activation of energy metabolism, protein synthesis, and RNA metabolism, by identifying high, but non-differential expression of the petF-3 gene encoding ferredoxin, as well as genes involved in photosynthesis ( $p s b E, p s b D-2)$, ribosomal proteins (rpmJ, $r p m I, r p s U)$, and an RNA-recognition motif containing protein (Syncc9605_1510) (Table S2).

We further characterized depth-specific cyanobacterial metabolism by visualizing the number of overexpressed and functionally (KEGG) defined transcripts from each depth (Fig. 3a). Accordingly, we generated a characteristic profile of metabolic functions per depth. In this visualization, the number of overexpressed genes at a certain depth, that were assigned to the presented pathways, is displayed as the intensity of coloration in the heatmap. Thus, when an equal number of (different) genes assigned to a certain pathway were determined as overexpressed in each of the depths, the pathway as a whole was not considered different between the 2 depths. For the $2.5 \mathrm{~m}$ sample, we used the 79 (68\%) of the 87 transcribed genes that matched KOs and that were overexpressed compared to $440 \mathrm{~m}$. Upregulated pathways at the surface were related to photosynthesis, chlorophyll biosynthesis, and energy metabolism (Fig. 3a). Glycine dehydrogenase, catalyzing the conversion of glycine to glyoxylate and ammonia and participating in photorespiration, was also overexpressed at $2.5 \mathrm{~m}$ (Fig. 3a, Table S2). At $2.5 \mathrm{~m}$ depth, high irradiance and super-saturated oxygen concentrations may activate photorespiratory pathways, as observed for Nodularia, a cyanobacterium forming summer surface blooms in the Baltic (Kopf et al. 2015). Other transcripts enriched in the $2.5 \mathrm{~m}$ sample were related to glutathione metabolism, terpenoid and peptidoglycan biosynthesis, aminoacyl-tRNA biosynthesis, protein export (signal recognition particle), and to isocitrate dehydrogenase (an enzyme involved in carbon metabolism) (Fig. 3a, Table S2).

Table 2. Data underlying the analysis of each taxon examined in detail in the framework of this study. The number of reads assigned to each taxonomic group at each depth, the number of transcripts detected, the number of genes these transcripts correspond to, and the number of KEGG orthologs (KOs) these genes matched are detailed

\begin{tabular}{|c|c|c|c|c|c|c|}
\hline Taxon & Selected reference & $\begin{array}{l}\text { No. of reads } \\
\text { at } 440 \mathrm{~m}\end{array}$ & $\begin{array}{l}\text { No. of reads } \\
\text { at } 2.5 \mathrm{~m}\end{array}$ & $\begin{array}{c}\text { No. of } \\
\text { transcripts }\end{array}$ & $\begin{array}{l}\text { No. of } \\
\text { genes }\end{array}$ & $\begin{array}{c}\text { No. of } \\
\text { KOs }\end{array}$ \\
\hline Cyanobacteria & Synechococcus CC9605 & 16403744 & 603887 & 2595 & 2055 & 1057 \\
\hline Mamiellales & Micromonas sp. RCC299 & 2526910 & 702446 & 1689 & 1289 & 689 \\
\hline SAR11 clade & Pelagibacter sp. HTCC7211 & 610309 & 188942 & 1150 & 934 & 717 \\
\hline Euryarchaeota & Customized reference & 245399 & 63897 & 805 & 724 & 447 \\
\hline Thaumarchaeota & Customized reference & 526638 & 30613 & 736 & 552 & 296 \\
\hline
\end{tabular}


a)

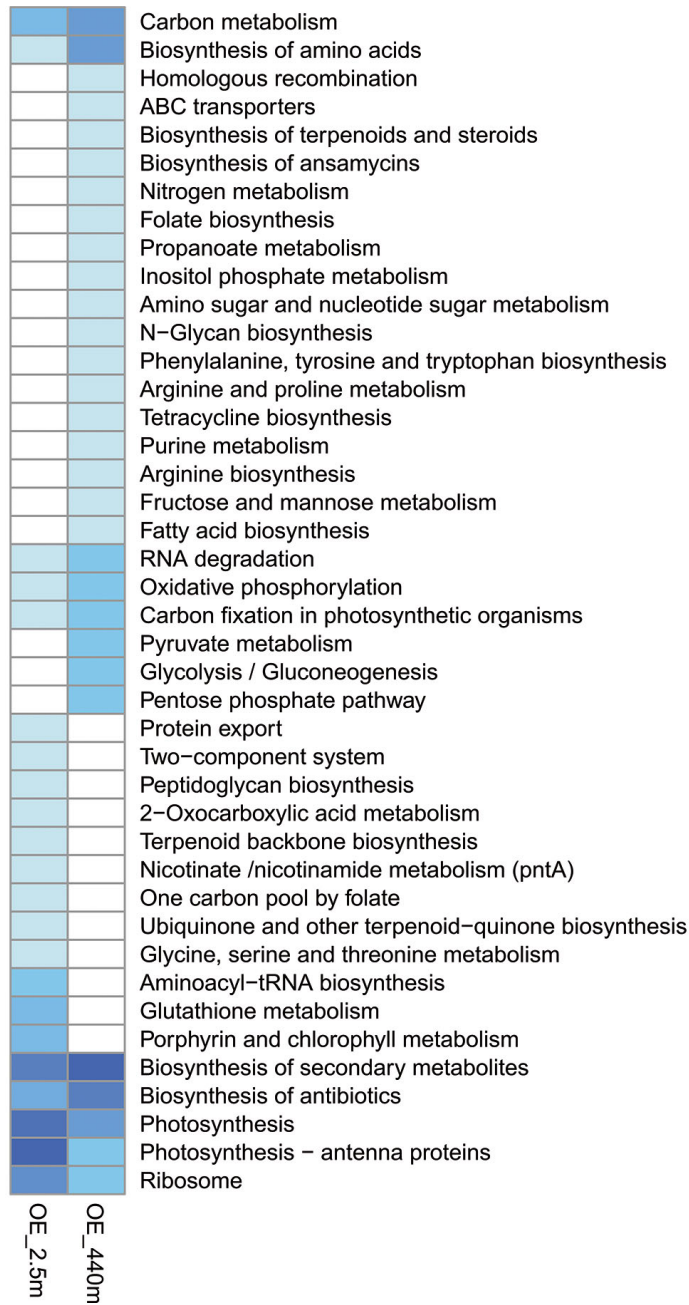

b)

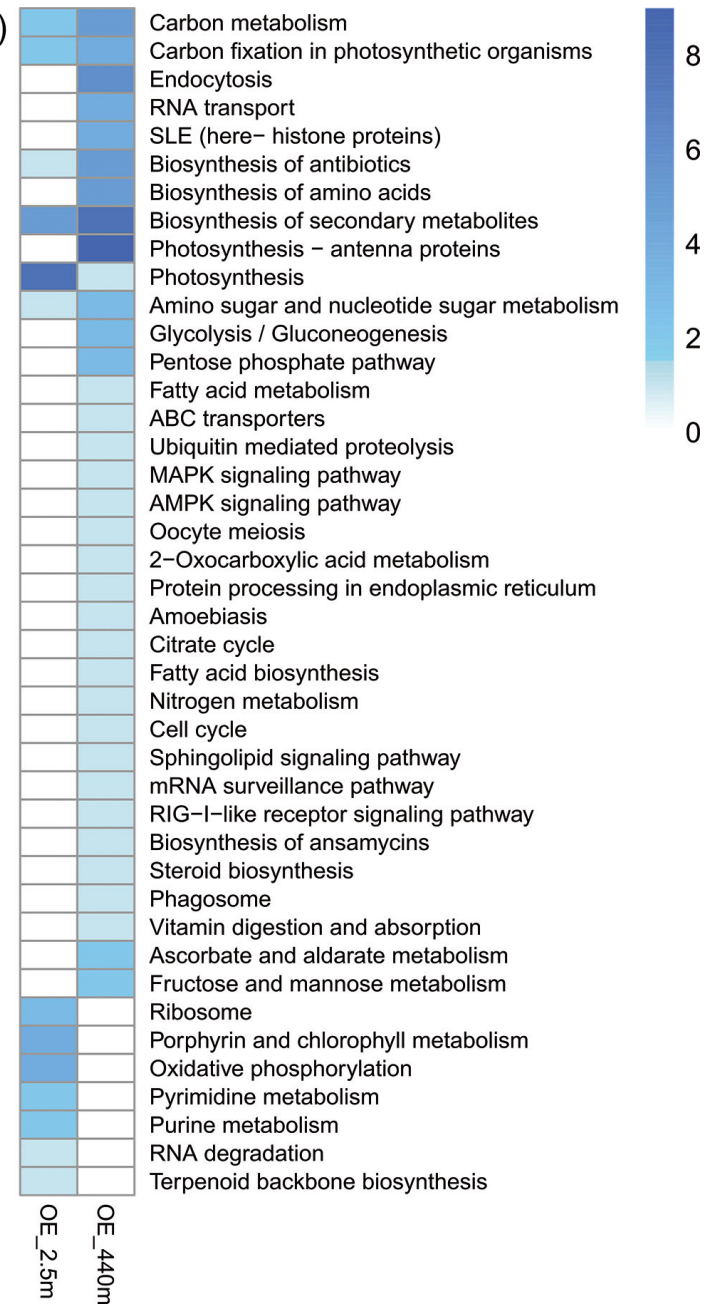

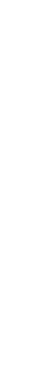


However, our reference Synechococcus CC9605 was isolated from an oligotrophic region in the California Current (Dufresne et al. 2008). In oligotrophic environments, cyanobacteria express reduced numbers of genes encoding organic matter transporters (Yelton et al. 2016). We therefore mapped all cyanobacterial reads from both depths and the $45 \mathrm{~m}$ sample mentioned above (Hou et al. 2016) against a customized database containing 26 gene sequences encoding transporters for organic compounds (see section 'Alignment of cyanobacterial reads to carbon transporters' in Supplement 1). The sequences were obtained from 2 Synechococcus genomes but included 17 'multispecies' sequences, i.e. sequences that are highly conserved among members of this clade. Of all cyanobacterial sequences, 0.004, 0.002 , and $0.003 \%$ were mapped to this database at $2.5,45$, and $440 \mathrm{~m}$, respectively. Thus, we detected only a marginal expression of transporters for organic compounds by cyanobacteria in our samples.

Cyanobacteria can also survive deprivation of light by metabolizing intracellular reserves of glycogen (Allen 1984). However, the genes encoding glycogen-degrading enzymes (glycogen/starch/ alpha-glucan phosphorylase and glycogen debranching enzymes) exhibited low expression at both depths at the time of sampling. In contrast, we detected highly expressed glycogen synthesis genes $g \lg B$ and $g \lg C$ (Tables S2 \& S3). The overexpression of genes involved in the pentose phosphate pathway at $440 \mathrm{~m}$, combined with scarce evidence for the expression of mixotrophy and/or glycogen-degradation related genes (summarized in Table S3), suggest that cyanobacteria in the mixed water column maintained active metabolism at the aphotic depth from carbohydrates synthesized via photosynthesis when the cells were exposed to the light.

Gene expression at $440 \mathrm{~m}$ was further characterized by the overexpression of Yfr103, a non-coding RNA of unknown function, yet highly abundant in both natural populations and in cultures of Synechococcus and Prochlorococcus (Voigt et al. 2014, Hou et al. 2016, Pfreundt et al. 2016a). Transcripts matching all 7 paralogs of yfr103 in Synechococcus CC9605 were at least an order of magnitude more abundant than all other transcripts. Moreover, overexpression at $440 \mathrm{~m}$ compared to $2.5 \mathrm{~m}$ (Table S2) suggests that Yfr103 may have an important role in the survival of cyanobacterial cells in the aphotic zone.

\section{Prasinophytes - Mamiellales}

At the time of sampling, picoeukaryotic microalgae dominated the phytoplankton biomass in the water column (Fig. 1) and contributed substantially to the total mRNA pool (Table 2). Of all eukaryotic reads, $74.4 \%$ were assigned to Mamiellales, with Micromonas and Ostreococcus recruiting $~ 95 \%$ of the sequences assigned to it. The Micromonas sp. RCC299 genome was used as reference for the detailed analysis of gene expression within this group (see Supplements 1 \& 2). We detected 1689 Mamiellales transcripts that represented 1289 genes annotated in the selected reference genome, of which 689 (53\%) were assigned to KOs (Table 2) and constructed a metabolic map (Fig. S4). Highly expressed genes were those involved in photosynthesis and carbon fixation, fatty acid biosynthesis, oxidative phosphorylation, and chlorophyll biosynthesis (Fig. S4). Analysis of all detected Mamiellales transcripts (including those that did not match a KO) further revealed a substantial, non-differential expression of ATPase and D1 protein-encoding genes (Table S4).

We generated a depth-specific functional profile based on the number of overexpressed transcripts assigned to each pathway at both depths (Fig. 3b). Out of 79 and 104 overexpressed transcripts at 2.5 and $440 \mathrm{~m}, 54(68 \%)$ and $44(42 \%)$ matched a $\mathrm{KO}$ at the respective depth and were used for further analysis. This analysis revealed that while gene expression at $2.5 \mathrm{~m}$ shifted towards energy metabolism and synthesis of some cellular components, highly expressed genes at $440 \mathrm{~m}$ were mostly involved in anabolic pathways and phagotrophy, and in transport of organic compatible solutes (see below).

Genes overexpressed at $2.5 \mathrm{~m}$ mapped mainly to functions related to energy metabolism, chlorophyll and protein biosynthesis, nucleotide metabolism, terpenoid backbone synthesis, and ribosome, porphyrin, and chlorophyll metabolism (Fig. 3b). Specific transcripts overexpressed at this depth encoded the D2 reaction center and several other photosystem II proteins, 2 F-type ATPase subunits, rRNA genes, and the large subunit of the carbon fixation enzyme ribulose bisphoshate carboxylase oxygenase (RuBis$\mathrm{CO}$ ) (Table S4). All rRNA genes that were differentially expressed were overexpressed at $2.5 \mathrm{~m}$, corresponding to the overrepresentation of KOs related to ribosomes, and pointing to higher translational activity at the surface (Fig. 3b, Table S4).

In contrast, the overexpressed Mamiellales transcripts from $440 \mathrm{~m}$ depth were related to endocytosis/phagosome, RNA transport, pentose phosphate 
pathway, biosynthesis of various metabolites and cell structures, glycolysis/gluconeogenesis, RNA surveillance, $\mathrm{ABC}$ transporters, and vitamin digestion and absorption (Fig. 3b). These results suggest that, similar to cyanobacteria, Mamiellales are metabolically active at the aphotic depth with a large fraction of genes assigned to anabolic processes. The upregulation of phagocytosis at $440 \mathrm{~m}$ suggests mixotrophy, which is a strategy applied by Micromonas under light or nutrient limitation (McKie-Krisberg \& Sanders 2014). Yet, comparable to the results obtained for cyanobacteria at this depth, we detected mostly low expression of organic-compound transporters in Mamiellales (Table S4). Additional genes overexpressed at $440 \mathrm{~m}$ encoded flagellar and motility related proteins, betaine/carnitine/choline transporter family proteins, 2 phosphate: $\mathrm{Na}^{+}$symporters, cold-shock DNA- and RNA-binding proteins ( $c s d$, MICPUN_83180), transcription factors, anaphasepromoting complex protein $c d c 20$, and histone proteins, indicating active cell division at depth in these photosynthetic organisms (Table S4). The overexpression of transcripts for the P:Na symporter and the flagellar basal body at $440 \mathrm{~m}$ depth implies motility (Throdsen 2012) and acquisition of phosphate by picoeukaryotes at depth. Overexpression of ubiquitin and histone proteins at $440 \mathrm{~m}$ indicates that proteasome and chromatin remodeling were active at the aphotic depth in Mamiellales while overexpression of betaine/carnitine/choline transporter suggests active osmoregulation and/or utilization of organic compounds for growth.

While the gene encoding the D2 (photosynthetic) protein was overexpressed at $2.5 \mathrm{~m}$, the most highly expressed light harvesting complex proteins were curiously overexpressed at $440 \mathrm{~m}$ (Table S4). The photosynthetic enzyme's RuBisCo small and large subunits (SSU, $r b c S$ gene and LSU, $r b c L$ ) were overexpressed at 440 and $2.5 \mathrm{~m}$, respectively. RuBisCo operates as a hexadecamer, made of 8 SSU and 8 LSU protein subunits that are expected to appear in equimolar ratios (reviewed by Hauser et al. 2015). Transcription, translation, and assembly of RuBisCo subunits are subjected to tight regulation (Gutteridge \& Gatenby 1995, Yosef et al. 2004). In eukaryotic algae, the genes are split between the chloroplast ( $r b c L$ ) and nuclear genome $(r b c S)$, and transcription may proceed independently of protein synthesis. In Prochlorococcus, transcript and protein levels were uncoupled for the large RuBisCo subunit (Waldbauer et al. 2012). It is intriguing, yet unclear, why some of these central photosynthetic genes were overexpressed in the dark at $440 \mathrm{~m}$, and further investigation is warranted.
SAR11

We detected 1150 SAR11 transcripts that represented 934 genes from the selected reference genome. Of these, we assigned $717(77 \%)$ to KOs (Table 2), providing the base for a metabolic map (Fig. S5). Genes related to fatty and amino acid biosynthesis, RNA polymerase, oxidative phosphorylation, TCA cycle, and glyoxylate and carbon metabolism were highly expressed (Fig. S5). Of the 75 and 80 genes overexpressed at 2.5 and $440 \mathrm{~m}$, respectively, 95 and $84 \%$ were assigned to a KO (Fig. 4a). At $2.5 \mathrm{~m}$ depth, pathways related to energy metabolism, protein export, RNA metabolism, and degradation were enriched (Fig. 4a). At $440 \mathrm{~m}$ depth, upregulated pathways included amino acid and lipopolysaccharide biosynthesis, the pentose phosphate pathway, fatty acid metabolism, and synthesis of glutathione, starch, and sucrose (Fig. 4a). The term 'amino acid metabolism' was the second and sixth most abundant KEGG term among overexpressed transcripts at 440 and $2.5 \mathrm{~m}$, respectively, with 14 overexpressed KOs at 440 and 7 at $2.5 \mathrm{~m}$. At least 9 of the 14 KOs assigned to amino acid metabolism and overexpressed at $440 \mathrm{~m}$ appear to encode enzymes promoting growth and synthesis of metabolites (such as putrescine and glutathione) in contrast with only 4 of the $7 \mathrm{KOs}$ overexpressed at $2.5 \mathrm{~m}$. This suggests that SAR11 metabolism is shifted toward amino acid degradation in the aphotic zone while it can take up and assimilate amino acids in the light (Malmstrom et al. 2004, 2005).

The availability of dissolved inorganic nitrogen and phosphorus can be critically limiting in oligotrophic environments, for both photoautotrophs and bacterioplankton (Moore et al. 2013). After temperature, nitrate was the main driver explaining the functional variations in 45 Red Sea metagenomic samples from both photic and aphotic depths (Thompson et al. 2017). While SAR11 can utilize different nitrogen and phosphorus forms (Thingstad et al. 1998, Malmstrom et al. 2005), the high expression of 2 different ammonium transporters (Table S5) indicated that SAR11 utilized ammonium at the time of sampling. It is likely that competition for this inorganic nitrogen source occurs with cyanobacteria and Thaumarchaeota, which also displayed high expression of ammonium transporters (Tables S2 \& S7).

In the Red Sea, the expression of nutrient transporters was negatively correlated with the ambient concentration of their respective substrates (Thompson et al. 2017). Availability of $\mathrm{N}$ and $\mathrm{P}$ and their limitation to microbial populations from the upper 


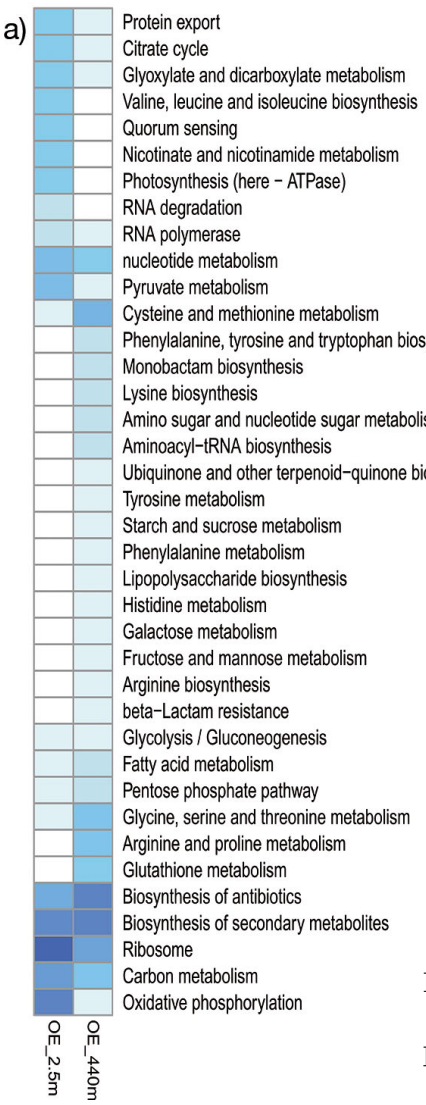

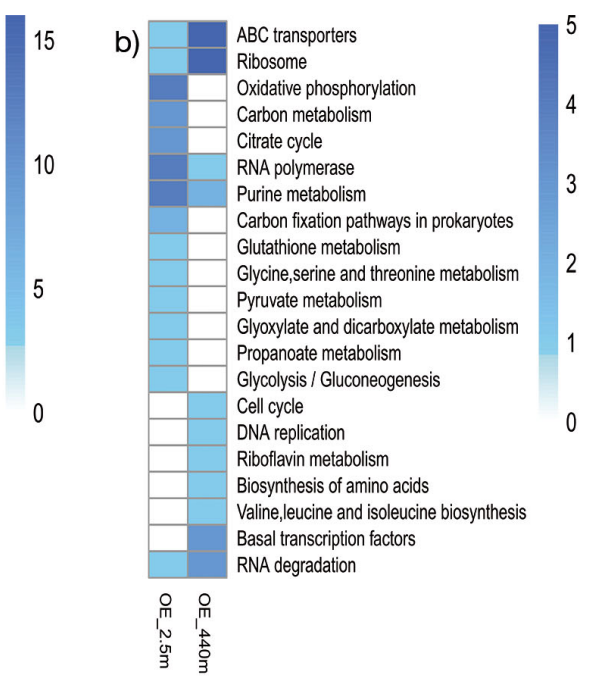

Fig. 4. KEGG pathways characterizing different depths in (a) SAR11, (b) Euryarchaeota, and (c) Thaumarchaeota. Pathway expression at $2.5 \mathrm{~m}$ is presented in the left column while $440 \mathrm{~m}$ pathways are presented in the right column. Color scale represents the number of differentially expressed transcripts assigned to each pathway. OE: overexpression surface layer of the Red Sea varies spatially and temporally (Lindell et al. 2005, Post 2005, Mackey et al. 2007, Thompson et al. 2013, 2017). SAR11 phosphonate and phosphate acquisition genes from a $50 \mathrm{~m}$ deep sample (mixed layer depth $=45 \mathrm{~m}$ ) were underrepresented when compared with other P-limited oligotrophic environments such as the Mediterranean Sea and the North Pacific Subtropical Gyre (Thompson et al. 2013). We observed substantial (yet non-differential) expression of a phosphate $A B C$ transporter (the PB7211_RS05420 gene), and overexpression of the $\mathrm{PhoH}$ phosphate starvation protein (Kim et al. 1993) at $440 \mathrm{~m}$. Accordingly, we postulate that SAR11 can experience $P$ starvation at the aphotic depth, and that it assimilates phosphate as a source of $\mathrm{P}$.

Pelagibacter sp. HTCC7211 switches to phosphonate consumption when starved of phosphate (Carini et al. 2014). We did not observe expression of genes related to phosphonate transport and utilization in SAR11, suggesting they were competing with Euryarchaeota over inorganic phosphate (see below). Phosphate uptake in heterotrophic populations, including SAR11, may enhance energy production in low-carbon environments as suggested by over- expression of HppA pyrophosphatase in an experimental manipulation of a SAR11-dominated natural bacterioplankton community (Rinta-Kanto et al. 2012). Our metatranscriptomes from both the photic and the aphotic depths displayed high expression of hppA in SAR11 (Table S5).

Organic compound transporters (subunits of the spermidine/putrescine and branched amino acid ABC transporters) were among the 20 most highly expressed genes in SAR11 (averaged values between 2.5 and $440 \mathrm{~m}$ ) yet were not differentially expressed between depths (Table S5). The respective transporter proteins encoded by these genes were also identified in a SAR11 metaproteome generated from a low-nutrient environment in the Sargasso Sea (Sowell et al. 2009). These different transporters contribute to a rather broad nutrient spectrum in an organism with such a small genome (Giovannoni et al. 2005b), enabling its ubiquitous distribution and evolutionary success in the oligotrophic ocean (Morris et al. 2002).

Transcripts related to energy and protein folding $(d n a K)$ characterized surface gene expression in SAR11, while expression of anabolic transcripts (genes involved in the synthesis of cellular envelope 
and lipopolysaccharides, amino acids, and nucleotides) predominated in the SAR11 population from the aphotic $440 \mathrm{~m}$ depth (Fig. 4a, Table S5). Similar to photoautotrophs, energy-starved SAR11 utilizes light for energy production (Steindler et al. 2011). Our observations, showing highly expressed genes for energy metabolism in the photic zone and anabolicrelated genes highly expressed aphotically, suggest that light availability modulates transcription during winter mixing. Activation of deoxyribodipyrimidine photolyase, which mitigates DNA UV damage by repairing UV-induced thymidine dimers, shows an acclimation response to high surface irradiance similar to that observed for surface microbial communities from the North Pacific Subtropical Gyre (DeLong et al. 2006). The high expression of this gene at $2.5 \mathrm{~m}$ is consistent with the high PAR measured during sampling $\left(1278 \mu \mathrm{mol}\right.$ photons $\mathrm{m}^{-2} \mathrm{~s}^{-1}$ at the surface; Pfreundt et al. 2014). In addition to high irradiance and UV damage, other stressors may also impact SAR11 activity as we observed high, non-differential, expression of the GroES chaperone (Hightower 1991, Frydman 2001) and the AAA+ FtsH proteases that are essential for proteolysis of regulatory proteins under environmental stress (Deuerling et al. 1995, Herman et al. 1995, Melchers et al. 1998). In bacteria, $\mathrm{ftsH}$ is involved in heat shock responses and in proteolysis of phage proteins (Langklotz et al. 2012) (Table S5).

\section{Archaea}

Uncultivated MG-II Euryarchaeota constituted the largest fraction of the microbial community, comprising $25-36 \%$ of the $16 \mathrm{~S}$ community at the time of sampling (Fig. 2a). Although much less abundant, the mRNA read abundance of Thaumarchaeota was comparable to that of Euryarchaeota (Fig. 2b). Representatives of these archaeal phyla are readily found in high abundances in several marine (and terrestrial) ecosystems (reviewed by Schleper et al. 2005). The metabolic lifestyle of these 2 archaeal phyla is not fully understood and probably includes different trophic lifestyles.

Thaumarchaeota include chemoautotrophic representatives that acquire energy via ammonia oxidation (Könneke et al. 2005), as supported by the wide distribution of thaumarchaeal ammonia oxidase genes in coastal (Monterey Bay) and pelagic (North Pacific Subtropical Gyre) environments (Mincer et al. 2007). Both Thaumarchaeota and Euryarchaeota can also consume amino acids, suggesting a hetero- or mixotrophic lifestyle in several of their representative species (Ouverney \& Fuhrman 2000, Herndl et al. 2005). Thaumarchaeota can use bicarbonate as a carbon resource, suggesting autotrophy (Ingalls et al. 2006). Yet, bicarbonate uptake rates are low compared to other prokaryotes (Herndl et al. 2005, Alonso-Sáez et al. 2012, Callieri et al. 2014). Urea uptake by Thaumarchaeota led to the hypothesis that urea represents an important resource for both inorganic carbon and nitrogen in some marine systems and suggested a solution for this apparent paradox (Alonso-Sáez et al. 2012).

Transcription profiles of the 2 archaeal phyla indicated differential utilization of nitrogen resources. In Euryarchaeota, genes related to the transport and utilization of amino acids and other nitrogen-containing organic compounds were highly expressed (Table S6). In contrast, these transcripts were not detected in Thaumarchaeota, and genes encoding ammonia and urea transporters were ranked fifth and ninth most highly expressed in this phylum, respectively (Table S7). While urea concentrations were not measured, high expression of the urea amidohydrolase gene (Table S7) in Thaumarchaeota suggests urea metabolism, perhaps as both a carbon and nitrogen resource (Alonso-Sáez et al. 2012). Additionally, high amt ammonia permease expression (Table S7) indicates that Thaumarchaeota also use ammonia as a nitrogen resource. In addition to its role as an electron donor for catabolism, expression of glutamine synthetase (Table S7) suggested ammonia was assimilated into glutamine.

Thaumarchaeota and Euryarchaeota also appear to utilize different phosphorus sources. In Thaumarchaeota, a $p h n D$ phosphonate transporter transcript was enriched and overexpressed at $440 \mathrm{~m}$ depth compared to $2.5 \mathrm{~m}$ (Table S7). In Euryarchaeota, we detected substantial expression of inorganic phosphate transporters, including a putative low affinity inorganic phosphate transporter and the PstS phosphate binding protein of an $\mathrm{ABC}$ transporter (Table S6).

The gene expression metabolic map of Euryarchaeota (Fig. S6) was based on 805 identified euryarchaeal transcripts which matched 724 genes in the reference pan-genome, 447 (62\%) of which corresponded to a KO (Table 2). Transcripts related to the biosynthesis of riboflavin (vitamin B2) and ubiquinone (a central compound of the aerobic respiratory electron transport chain) predominated. A list of all identified euryarchaeal transcripts, including those that were not assigned to the KEGG database (Table S6), revealed that 7 out of the top 20 ex- 
pressed euryarchaeal transcripts showed no differential expression between the different depths (Table S6). These transcripts included boxB (benzoyl-CoA oxygenase subunit beta), $f d x A$ (iron sulfur containing ferredoxin), $u b i B, p d x S / p d x 1$ (vitamin B6 synthesis), and ribA (riboflavin biosynthesis), implying utilization of benzoate as an organic carbon source (Zaar et al. 2004), and biosynthesis of vitamins $\mathrm{B} 2$ and $\mathrm{B} 6$.

Euryarchaea also revealed depth-specific expression, with 21 overexpressed genes with KO attribution at $2.5 \mathrm{~m}(78 \%$ of all overexpressed KOs at this depth). Upregulation was indicated in pathways related to glycolysis, oxidative phosphorylation, the TCA cycle, amino acid, glutathione and carbon metabolism (Fig. 4b). More specifically, KOs overexpressed at $2.5 \mathrm{~m}$ included: a broad specificity leucylaminopeptidase involved in protein housekeeping (eury_gene69), $p d h D$ pyruvate dehydrogenase gene (TCA cycle), ntpA and ntpB encoding V/A type ATPase (oxidative phosphorylation), and $s d h B / f r d B-$ the Fe-S subunit of succinate dehydrogenase/ fumarate reductase (TCA cycle, oxidative phosphorylation). Transcripts overexpressed at $2.5 \mathrm{~m}$, but without KEGG assignment (Table S6), included the $d n a K$ chaperone and the $p h r B$ photolyase involved in the UV stress response. Additional genes overexpressed at $2.5 \mathrm{~m}$ were involved in transcription (rpoA, gyrB), iron sulfur cluster assembly (sufD, also overexpressed in SAR11 at $2.5 \mathrm{~m}$ ), 3 F-type ATP synthase subunits, and a branched amino acid ABC transporter subunit (Table S6). Thus, surface enriched euryarchaeal transcripts indicated active energy metabolism, phosphate and amino acid transport, and stress responses.

In contrast, the $32 \mathrm{KOs}$ overexpressed at $440 \mathrm{~m}$ (68\% of all overexpressed euryarchaeal KOs at this depth) included genes assigned to pathways related to DNA replication and cell cycle, riboflavin metabolism (rfk), amino acid biosynthesis (ilvD), transcription initiation $(t b p)$, and RNA polymerase $(r p o A)$ (Fig. 4b, Table S6). Other overexpressed genes included livK (a component of the leucine transport system), pbuG (xanthine/uracil transport), and ftsZ (cell division), pointing to active nucleotide transport and cell division in the aphotic depth (Table S6).

Our results show that Euryarchaeota activated energy metabolism related genes at the photic depth while upregulating cell cycle genes, as well as genes involved in amino acid biosynthesis and transcription in the aphotic zone at $440 \mathrm{~m}$ depth (Fig. 4b, Table S6). Archaea can synthesize riboflavin (Fischer et al. 2004), and genes involved in pyridoxine biosynthesis were found in euryarchaeal genomes (Ehrenshaft et al. 1999, Osmani et al. 1999).

A total of 736 thaumarchaeal transcripts were detected, representing 552 genes in the selected thaumarchaeal pan-genome. Of these, 296 (54\%) matched a KO (Table 2) from which we constructed a metabolic map (Fig. S7). Here, we observed high expression of nadA, involved in the biosynthesis of the central intermediate nicotinamide adenine dinucleotide (NAD), folE, and $d x s$ (folate biosynthesis and thiamine metabolism), urease, the RNA polymerase omega subunit (rpb6), and genes related to nucleotide metabolism (Fig. S7, Table S7). Our observations suggest that Euryarchaeota and Thaumarchaeota may be a source of vitamins B1 (thiamin), B2, B6, and B9 (folate) in the water column, analogous to observations on the provision of vitamins such as thiamin (B1) (Paerl et al. 2017) and cobalamin (B12) (Bonnet et al. 2010) by certain members of the community. This is further supported by the discovery of a complete cobalamin biosynthesis pathway in Thaumarchaeota (Doxey et al. 2015).

Thaumarchaeal transcripts that were highly expressed at both depths included $2 \mathrm{amt}$ ammonia permease genes, an active urea transporter (Thaumarchaeote gene2780, GenBank accession: AIF12188.1), an $\operatorname{ars} R$ transcription factor (regulating among others the expression of the phoP alkaline phosphatase; Gao et al. 2011), and a blue copper domain-containing protein with a $\mathrm{C}$ terminal PEFG domain (cupredoxin, involved in unknown redox processes) (Table S7). These results suggest that nutrient uptake and assimilation indicated by genes for ammonia and urea transport, as well as energy metabolism and phosphate stress responses are important features of Thaumarchaeota that are independent of depth and light availability in this system.

The depth-specific functional profile (based on the number of transcripts recruited to pathways and overexpressed at each depth) was similar to that derived for Euryarchaeota. Upregulated genes were involved in energy and carbon metabolism pathways at the surface, while at $440 \mathrm{~m}$ depth anabolic pathways were upregulated (Fig. 4c). At $2.5 \mathrm{~m}$, the 5 overexpressed transcripts with $\mathrm{KO}$ attribution $(38.5 \%$ of the 14 overexpressed KOs at this depth) were assigned to the FtsH protease (cell division, stress response), rроH sigma-32 factor involved in heat shock response in Escherichia coli (Fujita \& Ishihama 1987), BIRC6/BRUCE (inhibitor of apoptosis and involved in proteolysis; Bartke et al. 2004), ubiquinolcytochrome $\mathrm{C}$ reductase (oxidative phosphorylation), and $p p d K$ encoding pyruvate phosphate dikinase 
producing phosphoenolpyruvate (PEP), a key compound in carbon metabolism and glycolysis.

Other genes overexpressed at $2.5 \mathrm{~m}$ (not matching a KO) included another urea transporter gene (GenBank accession AIF00862.1) and conserved proteins implicated in secretion (Table S7).

At $440 \mathrm{~m}, 41$ out of the 77 upregulated thaumarchaeal transcripts (53\%) were assigned to KOs, and were coupled with amino acid and secondary metabolite biosynthesis, DNA replication, transcription initiation, and induction of ribosomal proteins (Fig. 4c). Other upregulated pathways at $440 \mathrm{~m}$ included amino acid degradation, nitrogen metabolism (ammonia monooxygenase), nucleotide metabolism (comEBdCMP deaminase), proteasome, and ABC transporters ( $p h n D$ phosphonate transporter subunit). The $a m o B$ and $a m o X$ genes were also overexpressed at $440 \mathrm{~m}$ (ammonia monooxygenase subunits B and X), in contrast to the $a m o C$ subunit that was not differentially expressed. Differentially expressed sulfate adenylyltransferase (met3), adenylylsulfate kinase (cysC), and rhodanese-related sulfur transferase (Table S7) further indicated active sulfate assimilation and metabolism at $440 \mathrm{~m}$.

The archaeal profiles are consistent with the expression patterns obtained for SAR11 and cyanobacteria. The surface sample at $2.5 \mathrm{~m}$ was characterized by overexpressed energy metabolism-related genes while the predominant transcripts at $440 \mathrm{~m}$ depth were related to replication and synthesis (anabolism). Interpretation of this result is not as intuitive as for photoautotrophic organisms that utilize light to produce energy. Photosynthesis-derived matter (i.e. organic carbon) serves as an energy source for heterotrophic bacterioplankton and would thus be more available for heterotrophic utilization in the photic layer. The data indicate that during deep mixing, heterotrophs will increase energy (carbon) metabolism at the illuminated surface waters where carbon fixation occurs and enhance production of cellular components and secondary metabolites at the aphotic depth.

\section{Conclusions}

The present study provides insights into microbial gene expression and community composition in the photic and aphotic depths of a deep-mixed water column in the Gulf of Aqaba, Red Sea. For both photoautotropic and heterotrophic organisms, the RNA obtained at the surface was enriched with transcripts associated with energy metabolism and stress re- sponses, in contrast to high expression of genes associated with biosynthesis of secondary metabolites and cellular components, replication, and growth, which characterized the aphotic depth. Moreover, although picoeukaryotic algae of the Mamiellales group appeared to employ phagotrophy and/or mixotrophy at $440 \mathrm{~m}$ depth, we did not detect cyanobacterial gene expression linked to mixotrophy or the utilization of glycogen reserves. Combined with the negligible expression of transporters of organic compounds, our data suggest that photosynthates produced in the photic zone support cyanobacterial metabolism under aphotic conditions until the cells encounter light once more. Our data also reveal that archaea, primarily MG-II Euryarchaeota and Thaumarchaeota, comprised a large fraction of the microbial community at the time of sampling, and that niche partitioning based on differential utilization of nitrogen and phosphorus sources occurs between these 2 archaeal groups.

Acknowledgements. This work was supported by the Assemble (Association of European Marine Biological Laboratories) Infrastructure Access Call 5 to the Interuniversity Institute for Marine Sciences, Eilat, (IUI) Israel, by a BMBFMOST joint German-Israeli research project, project number GR2378/03F0640A to I.B.-F. and W.R.H., and by the EU project MaCuMBA (Marine Microorganisms: Cultivation Methods for Improving their Biotechnological Applications; grant agreement no: 311975) to W.R.H. The financial support to S.H. by the China Scholarship Council is gratefully acknowledged. This work is in partial fulfillment of a $\mathrm{PhD}$ requirement for D.M., who was also supported by a Presidents' Fellowship from Bar Ilan University. We thank the IUI logistic team and captain and crew of the RV 'Sam Rothberg' for help at sea and H. Elifantz for help during manuscript preparation.

\section{LITERATURE CITED}

Allen MM (1984) Cyanobacterial cell inclusions. Annu Rev Microbiol 38:1-25

Alonso-Sáez L, Waller AS, Mende DR, Bakker K and others (2012) Role for urea in nitrification by polar marine archaea. Proc Natl Acad Sci USA 109:17989-17994

* Bartke T, Pohl C, Pyrowolakis G, Jentsch S (2004) Dual role of BRUCE as an antiapoptotic IAP and a chimeric E2/E3 ubiquitin ligase. Mol Cell 14:801-811

* Béjà O, Aravind L, Koonin EV, Suzuki MT and others (2000) Bacterial rhodopsin: evidence for a new type of phototrophy in the sea. Science 289:1902-1906

Bonnet S, Webb EA, Panzeca C, Karl DM, Capone DG, Wilhelmy SAS (2010) Vitamin B12 excretion by cultures of the marine cyanobacteria Crocosphaera and Synechococcus. Limnol Oceanogr 55:1959-1964

Bowsher CG, Hucklesby DP, Emes MJ (1989) Nitrite reduction and carbohydrate metabolism in plastids purified from roots of Pisum sativum L. Planta 177:359-366

Brinkhoff T, Muyzer G (1997) Increased species diversity 
and extended habitat range of sulfur-oxidizing Thiomicrospira spp. Appl Environ Microbiol 63:3789-3796

Buchan A, LeCleir GR, Gulvik CA, González JM (2014) Master recyclers: features and functions of bacteria associated with phytoplankton blooms. Nat Rev Microbiol 12: 686-698

Buitenhuis ET, Li WKW, Vaulot D, Lomas MW and others (2012) Picophytoplankton biomass distribution in the global ocean. Earth Syst Sci Data 4:37-46

Callieri C, Coci M, Eckert EM, Salcher MM, Bertoni R (2014) Archaea and Bacteria in deep lake hypolimnion: in situ dark inorganic carbon uptake. J Limnol 73:47-54

* Carini P, White AE, Campbell EO, Giovannoni SJ (2014) Methane production by phosphate-starved SAR11 chemoheterotrophic marine bacteria. Nat Commun 5: 4346

* Carlson DF, Fredj E, Gildor H (2014) The annual cycle of vertical mixing and restratification in the Northern Gulf of Eilat/Aqaba (Red Sea) based on high temporal and vertical resolution observations. Deep-Sea Res I 84:1-17

Charuvaka A, Rangwala H (2011) Evaluation of short read metagenomic assembly. BMC Genomics 12(Suppl 2):S8

* Coe A, Ghizzoni J, LeGault K, Biller S, Roggensack SE, Chisholm SW (2016) Survival of Prochlorococcus in extended darkness. Limnol Oceanogr 61:1375-1388

WDeLong EF, Béjà O (2010) The light-driven proton pump proteorhodopsin enhances bacterial survival during tough times. PLOS Biol 8:e1000359

DeLong EF, Preston CM, Mincer T, Rich V and others (2006) Community genomics among stratified microbial assemblages in the ocean's interior. Science 311:496-503

* Deschamps P, Zivanovic Y, Moreira D, Rodriguez-Valera F, López-García P (2014) Pangenome evidence for extensive interdomain horizontal transfer affecting lineage core and shell genes in uncultured planktonic Thaumarchaeota and Euryarchaeota. Genome Biol Evol 6: 1549-1563

* Deuerling E, Paeslack B, Schumann W (1995) The ftsH gene of Bacillus subtilis is transiently induced after osmotic and temperature upshift. J Bacteriol 177:4105-4112

Dore JE, Houlihan T, Hebel DV, Tien G, Tupas L, Karl DM (1996) Freezing as a method of sample preservation for the analysis of dissolved inorganic nutrients in seawater. Mar Chem 53:173-185

* Doxey AC, Kurtz DA, Lynch MD, Sauder LA, Neufeld JD (2015) Aquatic metagenomes implicate Thaumarchaeota in global cobalamin production. ISME J 9:461-471

* Dufresne A, Ostrowski M, Scanlan DJ, Garczarek L and others (2008) Unraveling the genomic mosaic of a ubiquitous genus of marine cyanobacteria. Genome Biol 9:R90

Edgar RC (2013) UPARSE: highly accurate OTU sequences from microbial amplicon reads. Nat Methods 10:996-998

E Ehrenshaft M, Bilski P, Li MY, Chignell CF, Daub ME (1999) A highly conserved sequence is a novel gene involved in de novo vitamin B6 biosynthesis. Proc Natl Acad Sci USA 96:9374-9378

Ferreira AJS, Siam R, Setubal JC, Moustafa A and others (2014) Core microbial functional activities in ocean environments revealed by global metagenomic profiling analyses. PLOS ONE 9:e97338

*Ferrera I, Gasol JM, Sebastián M, Hojerová E, Koblížek M (2011) Comparison of growth rates of aerobic anoxygenic phototrophic bacteria and other bacterioplankton groups in coastal Mediterranean waters. Appl Environ Microbiol $77: 7451-7458$
Fischer M, Schott AK, Römisch W, Ramsperger A and others (2004) Evolution of vitamin $B_{2}$ biosynthesis. A novel class of riboflavin synthase in Archaea. J Mol Biol 343:267-278

Frydman J (2001) Folding of newly translated proteins in vivo: the role of molecular chaperones. Annu Rev Biochem 70:603-647

F Fujita N, Ishihama A (1987) Heat-shock induction of RNA polymerase sigma-32 synthesis in Escherichia coli: transcriptional control and a multiple promoter system. Mol Gen Genet MGG 210:10-15

Gao CH, Yang M, He ZG (2011) An ArsR-like transcriptional factor recognizes a conserved sequence motif and positively regulates the expression of phoP in mycobacteria. Biochem Biophys Res Commun 411:726-731

*Genin A, Lazar B, Brenner S (1995) Vertical mixing and coral death in the Red Sea following the eruption of Mount Pinatubo. Nature 377:507-510

KGiglione JF, Mevel G, Pujo-Pay M, Mousseau L, Lebaron P, Goutx M (2007) Diel and seasonal variations in abundance, activity, and community structure of particleattached and free-living bacteria in NW Mediterranean Sea. Microb Ecol 54:217-231

* Ghiglione JF, Palacios C, Marty JC, Mével G and others (2008) Role of environmental factors for the vertical distribution $(0-1000 \mathrm{~m})$ of marine bacterial communities in the NW Mediterranean Sea. Biogeosciences 5:1751-1764

*Giovannoni SJ, Bibbs L, Cho JC, Stapels MD and others (2005a) Proteorhodopsin in the ubiquitous marine bacterium SAR11. Nature 438:82-85

*Giovannoni SJ, Tripp HJ, Givan S, Podar M and others (2005b) Genome streamlining in a cosmopolitan oceanic bacterium. Science 309:1242-1245

*Gogou A, Sanchez-Vidal A, Durrieu de Madron X, Stavrakakis S and others (2014) Carbon flux to the deep in three open sites of the Southern European Seas (SES). J Mar Syst 129:224-233

* Gutteridge S, Gatenby AA (1995) Rubisco synthesis, assembly, mechanism, and regulation. Plant Cell 7:809

* Hartwell J, Bowsher CG, Emes MJ (1996) Recycling of carbon in the oxidative pentose phosphate pathway in nonphotosynthetic plastids. Planta 200:107-112

*Hauser T, Popilka L, Hartl FU, Hayer-Hartl M (2015) Role of auxiliary proteins in Rubisco biogenesis and function. Nat Plants 1:15065

* Heimbürger LE, Lavigne H, Migon C, D'Ortenzio F, Estournel C, Coppola L, Miquel JC (2013) Temporal variability of vertical export flux at the DYFAMED time-series station (Northwestern Mediterranean Sea). Prog Oceanogr 119:59-67

* Heise KP, Fuhrmann J (1994) Factors controlling mediumchain fatty acid synthesis in plastids from Cuphea embryos. Prog Lipid Res 33:87-95

* Herman C, Thévenet D, D'Ari R, Bouloc P (1995) Degradation of sigma 32, the heat shock regulator in Escherichia coli, is governed by HflB. Proc Natl Acad Sci USA 92: 3516-3520

*Herndl GJ, Reinthaler T, Teira E, van Aken H, Veth C, Pernthaler A, Pernthaler J (2005) Contribution of archaea to total prokaryotic production in the deep Atlantic Ocean. Appl Environ Microbiol 71:2303-2309

Hightower LE (1991) Heat shock, stress proteins, chaperones, and proteotoxicity. Cell 66:191-197

Hou S, Pfreundt U, Miller D, Berman-Frank I, Hess WR (2016) mdRNA-Seq analysis of marine microbial communities from the northern Red Sea. Sci Rep 6:35470 
Ingalls AE, Shah SR, Hansman RL, Aluwihare LI, Santos GM, Druffel ER, Pearson A (2006) Quantifying archaeal community autotrophy in the mesopelagic ocean using natural radiocarbon. Proc Natl Acad Sci USA 103: 6442-6447

Ionescu D, Penno S, Haimovich M, Rihtman B and others (2009) Archaea in the Gulf of Aqaba. FEMS Microbiol Ecol 69:425-438

Iverson V, Morris RM, Frazar CD, Berthiaume CT, Morales RL, Armbrust EV (2012) Untangling genomes from metagenomes: revealing an uncultured class of marine Euryarchaeota. Science 335:587-590

Kanehisa M, Goto S (2000) KEGG: Kyoto Encyclopedia of Genes and Genomes. Nucleic Acids Res 28:27-30

Kanehisa M, Sato Y, Morishima K (2016) BlastKOALA and GhostKOALA: KEGG tools for functional characterization of genome and metagenome sequences. J Mol Biol 428:726-731

Karl DM, Tien G (1992) MAGIC: a sensitive and precise method for measuring dissolved phosphorus in aquatic environments. Limnol Oceanogr 37:105-116

Karl DM, Tien G, Dore J, Winn CD (1993) Total dissolved nitrogen and phosphorus concentrations at US-JGOFS station ALOHA: Redfield reconciliation. Mar Chem 41: 203-208

Kiełbasa SM, Wan R, Sato K, Horton P, Frith MC (2011) Adaptive seeds tame genomic sequence comparison. Genome Res 21:487-493

Kim SK, Makino K, Amemura M, Shinagawa H, Nakata A (1993) Molecular analysis of the phoH gene, belonging to the phosphate regulon in Escherichia coli. J Bacteriol 175:1316-1324

Kirchman DL (2002) The ecology of Cytophaga-Flavobacteria in aquatic environments. FEMS Microbiol Ecol 39: 91-100

Klindworth A, Pruesse E, Schweer T, Peplies J, Quast C, Horn M, Glöckner FO (2013) Evaluation of general 16S ribosomal RNA gene PCR primers for classical and nextgeneration sequencing-based diversity studies. Nucleic Acids Res 41:e1

Könneke M, Bernhard AE, de la Torre JR, Walker $\mathrm{CB}$, Waterbury JB, Stahl DA (2005) Isolation of an autotrophic ammonia-oxidizing marine archaeon. Nature 437:543-546

Kopf M, Möke F, Bauwe H, Hess WR, Hagemann M (2015) Expression profiling of the bloom-forming cyanobacterium Nodularia CCY9414 under light and oxidative stress conditions. ISME J 9:2139-2152

Korlević M, Pop Ristova P, Garić R, Amann R, Orlić S (2015) Bacterial diversity in the South Adriatic Sea during a strong, deep winter convection year. Appl Environ Microbiol 81:1715-1726

Kriest I, Oschlies A (2007) Modelling the effect of cell-sizedependent nutrient uptake and exudation on phytoplankton size spectra. Deep-Sea Res I 54:1593-1618

Langklotz S, Baumann U, Narberhaus F (2012) Structure and function of the bacterial AAA protease FtsH. Biochim Biophys Acta 1823:40-48

Lazar B, Erez J, Silverman J, Rivlin T and others (2008) Recent environmental changes in the chemical-biological oceanography of the Gulf of Aqaba (Eilat). In: Por FD (ed) Aqaba-Eilat, the improbable gulf: environment, biodiversity and preservation. Magnes Press, Jerusalem, p 49-62

Li M, Baker BJ, Anantharaman K, Jain S, Breier JA, Dick GJ
(2015) Genomic and transcriptomic evidence for scavenging of diverse organic compounds by widespread deep-sea archaea. Nat Commun 6:8933

* Lindell D, Post AF (1995) Ultraphytoplankton succession is triggered by deep winter mixing in the Gulf of Aqaba (Eilat), Red Sea. Limnol Oceanogr 40:1130-1141

* Lindell D, Penno S, Al-Qutob M, David E, Rivlin T, Lazar B, Post AF (2005) Expression of the nitrogen stress response gene ntcA reveals nitrogen sufficient Synechococcus populations in the oligotrophic northern Red Sea. Limnol Oceanogr 50:1932

* Mackey KR, Labiosa RG, Calhoun M, Street JH, Post AF, Paytan A (2007) Phosphorus availability, phytoplankton community dynamics, and taxon-specific phosphorus status in the Gulf of Aqaba, Red Sea. Limnol Oceanogr 52:873-885

* Malmstrom RR, Kiene RP, Cottrell MT, Kirchman DL (2004) Contribution of SAR11 bacteria to dissolved dimethylsulfoniopropionate and amino acid uptake in the North Atlantic Ocean. Appl Environ Microbiol 70:4129-4135

Malmstrom RR, Cottrell MT, Elifantz H, Kirchman DL (2005) Biomass production and assimilation of dissolved organic matter by SAR11 bacteria in the Northwest Atlantic Ocean. Appl Environ Microbiol 71:2979-2986

* Marie D, Partensky F, Jacquet S, Vaulot D (1997) Enumeration and cell cycle analysis of natural populations of marine picoplankton by flow cytometry using the nucleic acid stain SYBR Green I. Appl Environ Microbiol 63: 186-193

* Massana R, Murray AE, Preston CM, DeLong EF (1997) Vertical distribution and phylogenetic characterization of marine planktonic archaea in the Santa Barbara Channel. Appl Environ Microbiol 63:50-56

McKie-Krisberg ZM, Sanders RW (2014) Phagotrophy by the picoeukaryotic green alga Micromonas: implications for Arctic Oceans. ISME J 8:1953-1961

Meeder E, Mackey KRM, Paytan A, Shaked Y and others (2012) Nitrite dynamics in the open ocean - clues from seasonal and diurnal variations. Mar Ecol Prog Ser 453: $11-26$

* Melchers K, Wiegert T, Buhmann A, Postius S, Schäfer KP, Schumann W (1998) The Helicobacter felis ftsH gene encoding an ATP-dependent metalloprotease can replace the Escherichia coli homologue for growth and phage $\lambda$ lysogenization. Arch Microbiol 169:393-396

* Mende DR, Waller AS, Sunagawa S, Järvelin AI and others (2012) Assessment of metagenomic assembly using simulated next generation sequencing data. PLOS ONE 7: e31386

*Merbt SN, Stahl DA, Casamayor EO, Martí E, Nicol GW, Prosser JI (2012) Differential photoinhibition of bacterial and archaeal ammonia oxidation. FEMS Microbiol Lett $327: 41-46$

Miller DR, Pfreundt U, Elifantz H, Hess WR, Berman-Frank I (2017) Microbial metatranscriptomes from the thermally stratified Gulf of Aqaba/Eilat during summer. Mar Genomics 32:23-26

* Mincer TJ, Church MJ, Taylor LT, Preston C, Karl DM, DeLong EF (2007) Quantitative distribution of presumptive archaeal and bacterial nitrifiers in Monterey Bay and the North Pacific Subtropical Gyre. Environ Microbiol 9: 1162-1175

*Moore CM, Mills MM, Arrigo KR, Berman-Frank I and others (2013) Processes and patterns of oceanic nutrient limitation. Nat Geosci 6:701-710 
Moore LR (2013) More mixotrophy in the marine microbial mix. Proc Natl Acad Sci USA 110:8323-8324

Morris RM, Rappe MS, Connon S, Virgin KL, Siebold WA, Carlson CA, Giovanonni SJ (2002) SAR11 clade dominates ocean surface bacterioplankton communities. Nature 420:806-810

Olson RJ, Chisholm SW, Zettler ER, Altabet MA, Dusenberry JA (1990) Spatial and temporal distributions of prochlorophyte picoplankton in the North Atlantic Ocean. Deep-Sea Res Part A 37:1033-1051

Osmani AH, May GS, Osmani SA (1999) The extremely conserved pyroA gene of Aspergillus nidulans is required for pyridoxine synthesis and is required indirectly for resistance to photosensitizers. J Biol Chem 274: 23565-23569

Ottesen EA, Young CR, Gifford SM, Eppley JM and others (2014) Multispecies diel transcriptional oscillations in open ocean heterotrophic bacterial assemblages. Science 345:207-212

Ouverney CC, Fuhrman JA (2000) Marine planktonic archaea take up amino acids. Appl Environ Microbiol 66: 4829-4833

Paerl RW, Bouget FY, Lozano JC, Vergé V and others (2017) Use of plankton-derived vitamin B1 precursors, especially thiazole-related precursor, by key marine picoeukaryotic phytoplankton. ISME J 11:753-765

* Partensky F, Hess WR, Vaulot D (1999) Prochlorococcus, a marine photosynthetic prokaryote of global significance. Microbiol Mol Biol Rev 63:106-127

* Pfreundt U, Miller D, Adusumilli L, Stambler N, BermanFrank I, Hess WR (2014) Depth dependent metatranscriptomes of the marine pico-/nanoplanktonic communities in the Gulf of Aqaba/Eilat during seasonal deep mixing. Mar Genomics 18:93-95

* Pfreundt U, Spungin D, Bonnet S, Berman-Frank I, Hess WR (2016a) Global analysis of gene expression dynamics within the marine microbial community during the VAHINE mesocosm experiment in the southwest Pacific. Biogeosciences 13:4135-4149

* Pfreundt U, Van Wambeke F, Caffin M, Bonnet S, Hess WR (2016b) Succession within the prokaryotic communities during the VAHINE mesocosms experiment in the New Caledonia lagoon. Biogeosciences 13:2319-2337

Pinto FL, Thapper A, Sontheim W, Lindblad P (2009) Analysis of current and alternative phenol based RNA extraction methodologies for cyanobacteria. BMC Mol Biol 10: 79-86

Post AF (2005) Nutrient limitation of marine cyanobacteria. In: Huisman J, Matthijs HCP, Visser PM (eds) Harmful cyanobacteria. Springer, Dordrecht, p 87-107

Raven JA, Kübler JE (2002) New light on the scaling of metabolic rate with the size of algae. J Phycol 38:11-16

Reiss Z, Hottinger L (1984) The Gulf of Aqaba, ecological micropaleontology. Springer, Berlin

Rinta-Kanto JM, Sun S, Sharma S, Kiene RP, Moran MA (2012) Bacterial community transcription patterns during a marine phytoplankton bloom. Environ Microbiol 14: 228-239

Robinson MD, Oshlack A (2010) A scaling normalization method for differential expression analysis of RNA-seq data. Genome Biol 11:R25

Schleper C, Jurgens G, Jonuscheit M (2005) Genomic studies of uncultivated archaea. Nat Rev Microbiol 3:479-488

Schott F, Leaman KD (1991) Observations with moored acoustic Doppler current profilers in the convection re- gime in the Golfe du Lion. J Phys Oceanogr 21:558-574

Severin T, Conan P, Durrieu de Madron X, Houpert L and others (2014) Impact of open-ocean convection on nutrients, phytoplankton biomass and activity. Deep-Sea Res I 94:62-71

* Severin T, Sauret C, Boutrif M, Duhaut T and others (2016) Impact of an intense water column mixing $(0-1500 \mathrm{~m})$ on prokaryotic diversity and activities during an openocean convection event in the NW Mediterranean Sea. Environ Microbiol 18:4378-4390

* Sharma CM, Hoffmann S, Darfeuille F, Reignier J and others (2010) The primary transcriptome of the major human pathogen Helicobacter pylori. Nature 464:250-255

Sosik HM, Olson RJ, Armbrust EV (2010) Flow cytometry in phytoplankton research. In: Suggett DJ, Prášil O, Borowitzka MA (eds) Chlorophyll a fluorescence in aquatic sciences: methods and applications. Springer, Dordrecht, p 171-185

* Sowell SM, Wilhelm LJ, Norbeck AD, Lipton MS and others (2009) Transport functions dominate the SAR11 metaproteome at low-nutrient extremes in the Sargasso Sea. ISME J 3:93-105

Steindler L, Schwalbach MS, Smith DP, Chan F, Giovannoni SJ (2011) Energy starved Candidatus Pelagibacter ubique substitutes light-mediated ATP production for endogenous carbon respiration. PLOS ONE 6:e19725

* Swan BK, Tupper B, Sczyrba A, Lauro FM and others (2013) Prevalent genome streamlining and latitudinal divergence of planktonic bacteria in the surface ocean. Proc Natl Acad Sci USA 110:11463-11468

Tamburini C, Garel M, Al Ali B, Mérigot B, Kriwy P, Charrière $B$, Budillon G (2009) Distribution and activity of bacteria and archaea in the different water masses of the Tyrrhenian Sea. Deep-Sea Res II 56:700-712

Tarazona S, García-Alcalde F, Dopazo J, Ferrer A, Conesa A (2011) Differential expression in RNA-seq: a matter of depth. Genome Res 21:2213-2223

*Tatusova T, Ciufo S, Fedorov B, O'Neill K, Tolstoy I (2014) RefSeq microbial genomes database: new representation and annotation strategy. Nucleic Acids Res 42:D553-D559

* Teeling H, Fuchs BM, Becher D, Klockow C and others (2012) Substrate-controlled succession of marine bacterioplankton populations induced by a phytoplankton bloom. Science 336:608-611

* Thingstad TF, Zweifel UL, Rassoulzadegan F (1998) P limitation of heterotrophic bacteria and phytoplankton in the northwest Mediterranean. Limnol Oceanogr 43:88-94

* Thompson LR, Field C, Romanuk T, Ngugi D, Siam R, El Dorry H, Stingl U (2013) Patterns of ecological specialization among microbial populations in the Red Sea and diverse oligotrophic marine environments. Ecol Evol 3: 1780-1797

Thompson LR, Williams GJ, Haroon MF, Shibl A and others (2017) Metagenomic covariation along densely sampled environmental gradients in the Red Sea. ISME J 11: 138-151

Throdsen J (2012) The planktonic marine flagellates. In: Tomas CR (ed) Marine phytoplankton: a guide to naked flagellates and coccolithophorids. Academic Press, San Diego, CA, p 7-131

Veldhuis MJW, Kraay GW (1990) Vertical distribution and pigment composition of a picoplanktonic prochlorophyte in the subtropical North Atlantic: a combined study of HPLC-analysis of pigments and flow cytometry. Mar Ecol Prog Ser 68:121-127 
Voigt K, Sharma CM, Mitschke J, Joke Lambrecht S, Voß B, Hess WR, Steglich C (2014) Comparative transcriptomics of two environmentally relevant cyanobacteria reveals unexpected transcriptome diversity. ISME J 8:2056-2068

Waldbauer JR, Rodrigue S, Coleman ML, Chisholm SW (2012) Transcriptome and proteome dynamics of a lightdark synchronized bacterial cell cycle. PLOS ONE 7: e43432

Wolf-Vecht A, Paldor N, Brenner S (1992) Hydrographic indications of advection/convection effects in the Gulf of Elat. Deep-Sea Res Part A 39:1393-1401

Yamada T, Letunic I, Okuda S, Kanehisa M, Bork P (2011) iPath2.0: interactive pathway explorer. Nucleic Acids

Editorial responsibility: Zoe Finkel,

Sackville, New Brunswick, Canada
Res 39:W412-W415

* Yelton AP, Acinas SG, Sunagawa S, Bork P, Pedrós-Alió C, Chisholm SW (2016) Global genetic capacity for mixotrophy in marine picocyanobacteria. ISME J 10: 2946-2957

Yosef I, Irihimovitch V, Knopf JA, Cohen I and others (2004) RNA binding activity of the ribulose-1,5-bisphosphate carboxylase/oxygenase large subunit from Chlamydomonas reinhardtii. J Biol Chem 279: 10148-10156

Zaar A, Gescher J, Eisenreich W, Bacher A, Fuchs G (2004) New enzymes involved in aerobic benzoate metabolism in Azoarcus evansii. Mol Microbiol 54:223-238

Submitted: March 28, 2017; Accepted: August 31, 2017

Proofs received from author(s): November 19, 2017 